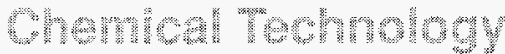

Whyilum

Chemical Technology Division

Chemical Technology Division

Chemical Technology Division

Chemical Technology

DWiston

Chemical Technology

Diviston

Chemical Technology

Division

Chemical Technology

Division

Chembel Technology

Dlübion

Chemisal technology

Diviston

Chemical Technology

Division

Chemical Technology

Division

Chemical Technology

Dhuision

Chemical Technology

Division
Magnetically Assisted Chemical Separation (MACS) Process: Preparation and Optimization of Particles for Removal of Transuranic Elements

by L. Nuñez, M. Kaminski, C. Bradley, B. A. Buchholz, S. Landsberger, S. B. Aase, H. E. Tuazon, and G. F. Vandegrift

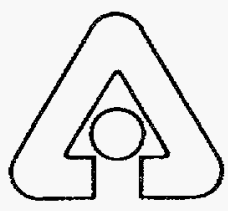

Argonne National Laboratory, Argonne, Illinois 60439

operated by The University of Chicago

for the United States Department of Energy under Contract W-31-109-Eng-38

Chemical Technology

Division

Chemical Teohnology

Division

Chemical Technology

Division

Chemical Technology

MASTER

Divislon 
Argonne National Laboratory, with facilities in the states of Illinois and Idaho, is owned by the United States government, and operated by The University of Chicago under the provisions of a contract with the Department of Energy.

\section{DISCLAIMER}

This report was prepared as an account of work sponsored by an agency of the United States Government. Neither the United States Government nor any agency thereof, nor any of their employees, makes any warranty, express or implied, or assumes any legal liability or responsibility for the accuracy, completeness, or usefulness of any information, apparatus, product, or process disclosed, or represents that its use would not infringe privately owned rights. Reference herein to any specific commercial product, process, or service by trade name, trademark, manufacturer, or otherwise, does not necessarily constitute or imply its endorsement, recommendation, or favoring by the United States Government or any agency thereof. The views and opinions of authors expressed herein do not necessarily state or reflect those of the United States Government or any agency thereof.

Reproduced from the best available copy.

Available to DOE and DOE contractors from the

Office of Scientific and Technical Information

P.O. Box 62

Oak Ridge, TN 37831

Prices available from (615) 576-8401

Available to the public from the

National Technical Information Service

U.S. Department of Commerce

5285 Port Royal Road

Springfield, VA 22161 


\section{DISCLAMMER}

Portions of this document may be illegible in electronic image products. Images are produced from the best available original document. 
Distribution Category:

Defense Waste Management

(UC-721)

ANL-95/1

\section{ARGONNE NATIONAL LABORATORY \\ 9700 South Cass Avenue \\ Argonne, IL 60439}

\section{MAGNETICALLY ASSISTED CHEMICAL SEPARATION (MACS) PROCESS: PREPARATION AND OPTIMIZATION OF PARTICLES FOR REMOVAL OF TRANSURANIC ELEMENTS}

by

L. Nuñez, M. Kaminski, C. Bradley, B. A. Buchholz, S. Landsberger, ${ }^{*}$ S. B. Aase, H. E. Tuazon, and G. F. Vandegrift

Chemical Technology Division

May 1995

\footnotetext{
* University of Illinois, Urbana, IL.
} 


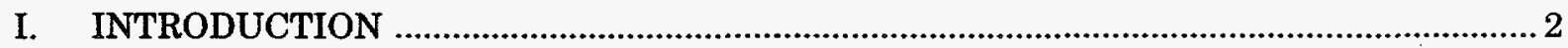

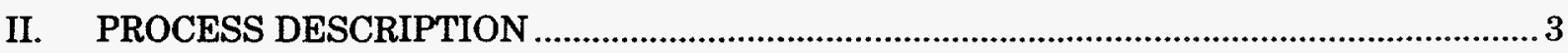

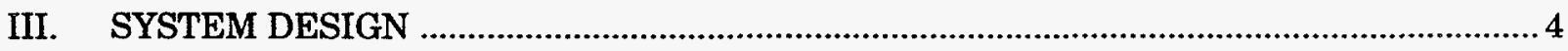

IV. PREPARATION AND OPTIMIZATION OF TRU REMOVAL PARTICLES ....................... 6

A. Particle Selection Based on Morphology Studies and Magnetite Distribution ................ 6

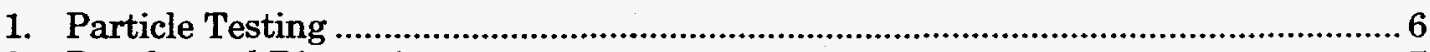

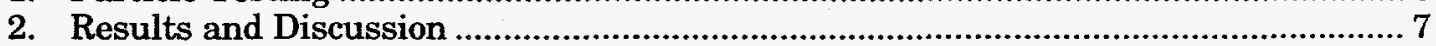

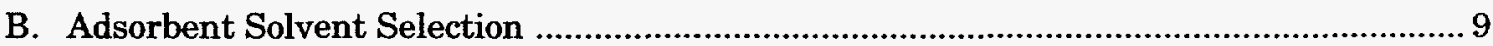

C. Optimization of Extractant Adsorption .................................................................... 10

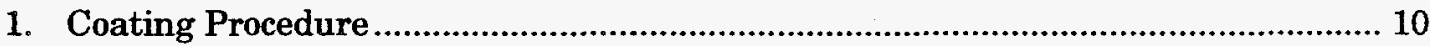

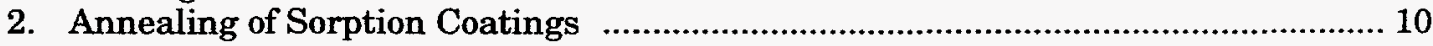

D. Nitric Acid Effects on Partitioning of TRU Elements ............................................. 10

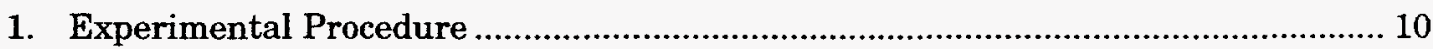

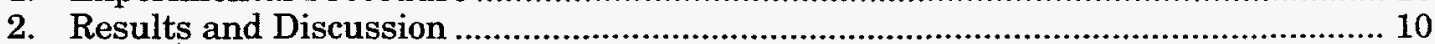

E. Dependency of TRU Separation on Solvent Coating Thickness and Composition ........ 12

F. Effect of Temperature on TRU Extraction ................................................................... 13

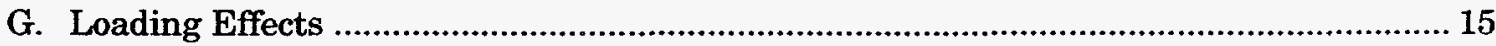

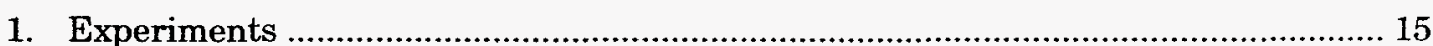

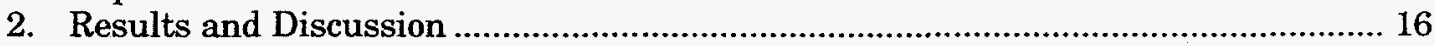

V. SIMULANT WASTE STREAM TESTING ON MACS PARTICLES …............................ 20

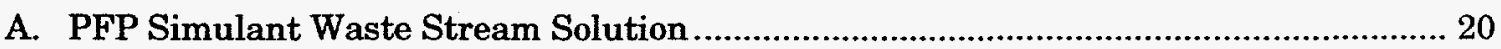

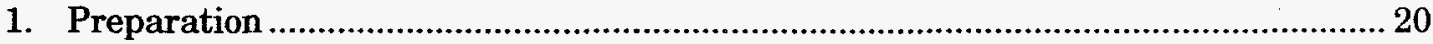

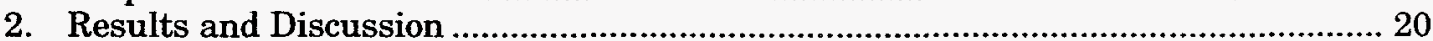

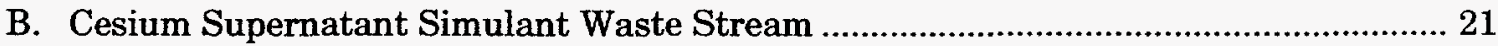

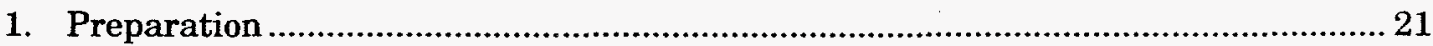

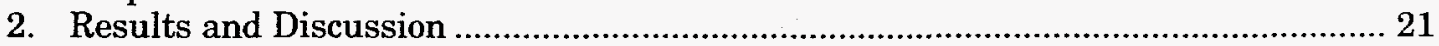

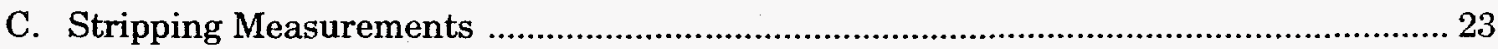

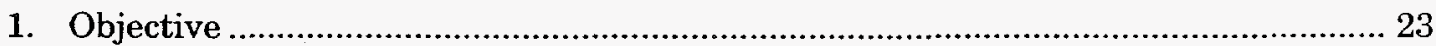

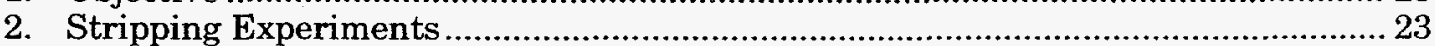

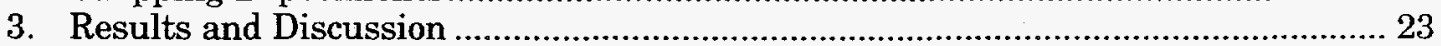




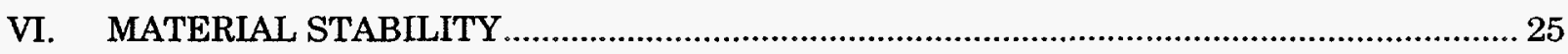

A. Chemical Stability of Particles - Dissolution in Nitric Acid ......................................... 25

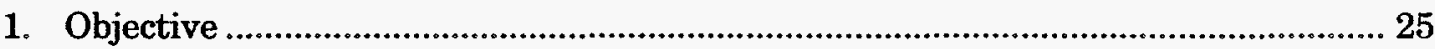

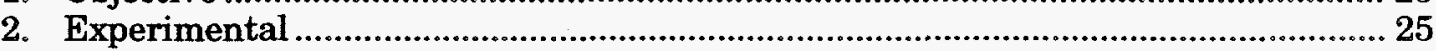

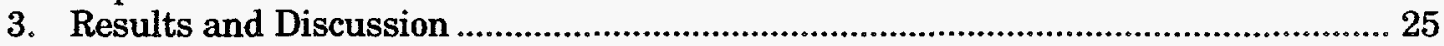

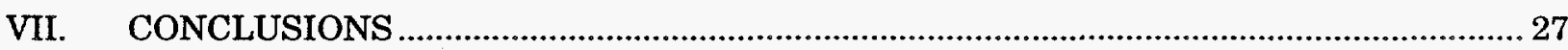

APPENDIX A. NATURE OF THE SUPERPARAMAGNETIC PARTICLE AND SELECTION FOR MACS APPLICATIONS ....................................... 28

APPENDIX B. ERROR CALCULATION IN PARTITION COEFFICIENT ............................... 35

APPENDIX C. OPTIMIZATION OF PARTICLE PREPARATION …................................. 38

APPENDIX D. NEUTRON ACTIVATION ANALYSIS ................................................. 40

APPENDIX E. ERROR FUNCTION FOR $\mathrm{K}_{\mathrm{d}}$ STRIP EXPERIMENTS ............................. 45

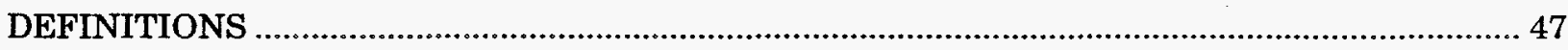

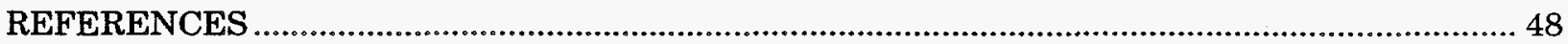




\section{LIST OF FIGURES}

No.

$\underline{\text { Title }}$

II-1. Concept Diagram of MACS Process.

III-1. Process Diagram for MACS Fluidized Bed ….......................................................... 4

IV-1. TEM Micrographs of Magnetic Particles ................................................................ 8

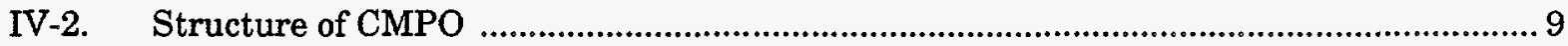

IV-3. $\quad \mathrm{K}_{\mathrm{d}}$ vs. Nitric Acid Concentration for ${ }^{241} \mathrm{Am}$ and $238 \mathrm{Pu}$ for $1.0 \mathrm{M}$

CMPO/TBP Coatings on Magnetic Particles at $25^{\circ} \mathrm{C}$

IV-4. Plot of Dependence of $\mathrm{K}_{\mathrm{d}}$ on Calculated Coating Thickness for ${ }^{241} \mathrm{Am}$...................... 14

IV-5. The $\mathrm{K}_{\mathrm{d}}$ Values for Americium for $1 \underline{\mathrm{M}}$ CMPO/TBP vs. Nitric Acid

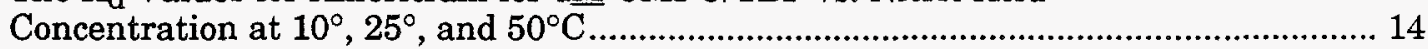

IV-6. Distribution of Europium as a Function of Loading Stage.......................................... 16

IV-7. Low Magnification View of Charcoal Particles and Associated Magnetite Particles

IV-8. A Neodymium-Complexed Charcoal Particle _........................................................... 18

IV-9. EDS Spectra from Neodymium-Complexed Charcoal Particle ...................................... 19

V-1. Americium and Plutonium Separation from PFP Simulant Solution at $25^{\circ} \mathrm{C}$ by CMPO/TBP-Coated Particles

V-2. Americium Separation from Hanford Tank Supernatant Simulant at $25^{\circ} \mathrm{C}$ by MACS Particles Loaded with CMPO/TBP

VI-1. Dissolution of Iron from Magnetite vs. Nitric Acid Concentration ............................... 25

VI-2. TEM Micrograph of Magnetic Particles with Polymeric Coating ................................ 26

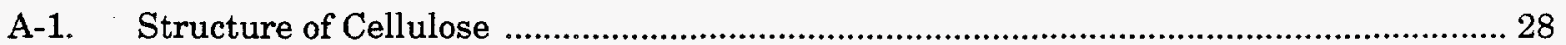

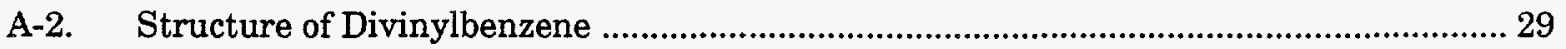

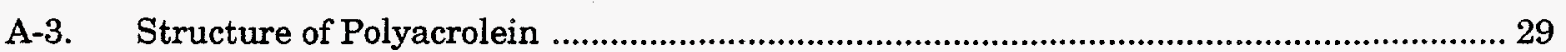

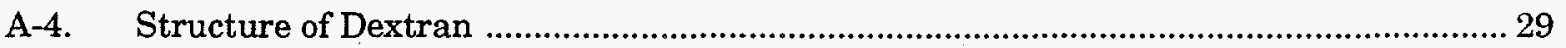

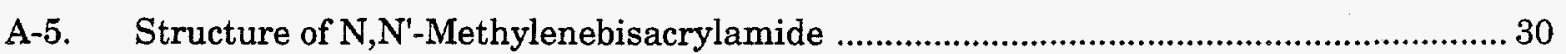

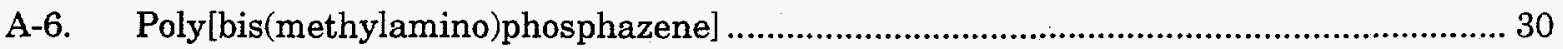

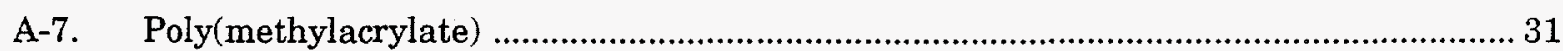

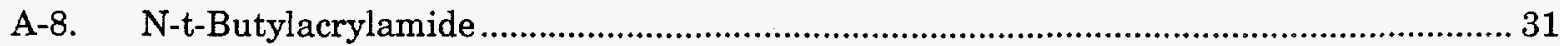


No. Title $\underline{\text { Page }}$

A-9. Methacrylamide 31

A-10. Variations of the Polyacrolein Structure 31

\section{LIST OF TABLES}

No.

Title

IV-1. Magnetic Particles Selected for Microscopic Study 6

IV-2. Dependency of $K_{d}$ on Coating Thickness and Composition ....................................... 13

IV-3. SST Dissolved Sludge Simulant Composition....................................................... 15

V-1. PFP Simulant Waste Composition .................................................................... 20

V-2. Hanford Tank Cesium Supernatant Simulant Composition........................................ 22

V-3. Stripping $\mathrm{K}_{\mathrm{d}}$ for ${ }^{238} \mathrm{Pu}$ in PFP Simulant.............................................................. 23

A-1. Microparticle Coating Contractors and Consultants ................................................. 32

A:2. Technical Matters ......................................................................................................... 34

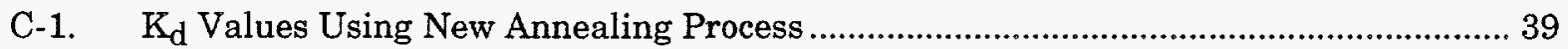

C-2. Partition Coefficients for TRU Extraction in $2 \mathrm{M} \mathrm{HNO}_{3}$ with MACS Process and Comparison with Solvent Extraction Distribution Ratios 39

E-1. 1.0 M CMPO Extraction and Stripping Data........................................................ 46 


\title{
MAGNETICALLY ASSISTED CHEMICAL SEPARATION (MACS) PROCESS: \\ PREPARATION AND OPTIMIZATION OF PARTICLES \\ FOR REMOVAL OF TRANSURANIC ELEMENTS
}

by

L. Nuñez, M. Kaminski, C. Bradley, B. A. Buchholz, S. Landsberger,

S. B. Aase, H. E. Tuazon, and G. F. Vandegrift

\begin{abstract}
The Magnetically Assisted Chemical Separation (MACS) process combines the selectivity afforded by solvent extractants with magnetic separation by using specially coated magnetic particles to provide a more efficient chemical separation of transuranic (TRU) elements, other radionuclides, and heavy metals from waste streams. Development of the MACS process uses chemical and physical techniques to elucidate the properties of particle coatings and the extent of radiolytic and chemical damage to the particles, and to optimize the stages of loading, extraction, and particle regeneration. This report describes the development of a separation process for TRU elements from various high-level waste streams.

Polymer-coated ferromagnetic particles with an adsorbed layer of octyl(phenyl)-N,N-diisobutylcarbamoylmethylphosphine oxide (CMPO) diluted with tributyl phosphate (TBP) were evaluated for use in the separation and recovery of americium and plutonium from nuclear waste solutions. Due to their chemical nature, these extractants selectively complex americium and plutonium contaminants onto the particles, which can then be recovered from the solution by using a magnet. The partition coefficients were larger than those expected based on liquid/liquid extractions, and the extraction proceeded with rapid kinetics. Extractants were stripped from the particles with alcohols and 400 -fold volume reductions were achieved. Particles were more sensitive to acid hydrolysis than to radiolysis. Overall, the optimization of a suitable MACS particle for TRU separation was achieved under simulant conditions, and a MACS unit is currently being designed for an in-lab demonstration.
\end{abstract}




\section{INTRODUCTION}

Nuclear fuel reprocessing and nuclear weapons manufacture have produced large volumes of liquid wastes, and many U.S. Department of Energy (DOE) sites have aqueous radioactive, hazardous, and mixed wastes stored in tanks, awaiting treatment and ultimate disposal. One example is the millions of gallons of tank waste from the plutonium-finishing plant at Hanford. The sludges and supernatants in the underground storage tanks at Hanford are high-level wastes (HLWs) because they contain $\mathrm{Cs}, \mathrm{Sr}$, and transuranic (TRU) radioisotopes with long half-life, even though these elements are present only in low concentrations.

Separation and concentration of the TRU elements will allow the remaining nuclear wastes to be disposed of (more economically) as low-level waste (LLW), while the resulting TRU concentrate can be contained in the final waste form (glass) for disposal in a deep geological repository. The TRUEX process was developed to separate TRU elements from radioactive liquid waste [HORWITZA].

This project is involved in the development of compact, economical, in-tank or near-tank processes for the on-site removal of contaminants, particularly TRU elements, from tank sludges and supernatants at Hanford and other DOE sites.

The magnetically assisted chemical separation process (MACS) uses magnetic beads coated with (1) a selective ion exchange material or an organic complexant-containing solvent that will complex $\mathrm{Cs}$ and $\mathrm{Sr}$, or (2) solvents for selective separation of $\mathrm{Cs}, \mathrm{Sr}$, TRU elements or other species. The beads are formed by coating iron or another magnetic material with either an organic polymer or an ion exchange resin. The resin is attached by an adhesive or by direct bonding. Organic solvents can be adsorbed onto the polymeric surface by contacting the beads with a solution of the solvent in a volatile diluent and then removing the diluent by evaporation. These coatings selectively separate the contaminants onto the beads according to their chemical nature, and the beads can subsequently be recovered from the tank by use of a magnet.

After removal, the contaminants can either (1) be left on the loaded beads and processed for disposal or (2) be stripped into a small volume of solution to regenerate the extracting beads. For example, in the TRUEX process, the solvent, octyl(phenyl)-N,N-diisobutylcarbamoylmethylphosphine oxide (CMPO) in tributyl phosphate (TBP), can be washed from the beads with a volatile diluent (an alcohol or hydrocarbon). The alcoholic diluent also reduces the affinity of the solvent for TRU elements, which can be stripped from the solvent with dilute acid. Evaporation of the alcohol regenerates the beads.

The MACS technique is a simple, cost-effective, and compact process for separation of radionuclides from waste without production of large waste streams, and it is applicable to many DOE liquid TRU wastes. Process development involves research into (1) coating the magnetic particles, (2) optimizing separation capabilities of the magnetic particles, (3) separating the particles from solution by using an applied magnetic field, (4) stripping the particles for regeneration, and (5) measuring radiation damage to particles. 


\section{PROCESS DESCRIPTION}

The basis of the MACS process is described in the literature [NUNEZ-1993]. The technique is still in the developmental stage. Figure II-1 shows a diagram of the MACS concept for TRU removal. In the MACS process, the contaminated aqueous stream is added to a treatment tank that can also be used for the stripping stage. Magnetic particles coated with CMPO in TBP (CMPO/TBP) are added to the treatment tank to separate the TRU from the liquid waste. To maintain particle suspension, the tank contents can be mixed by mechanical stirring, magnetic fluidization, or other methods. After extraction, the particles are magnetically separated by one of three methods: (1) placing a magnetic field around the treatment tank, (2) pumping the solution through a magnetic filter (e.g., commercially available magnetic units), or (3) introducing a magnet inside the tank. The waste solution (now decontaminated) is withdrawn and can be treated as low-level waste. The TRUloaded particles are either sent to high-level or TRU waste disposal facilities or left in the tank for stripping with a smaller volume (compared to the original feed volume) of liquid.

Because of its simplicity, use of the MACS process should (1) reduce the complexity of equipment compared to that required for solvent extraction and ion exchange, and (2) facilitate scaleup. One of the wastes that the MACS process could successfully treat is that from the neutralized Plutonium Finishing Plant (PFP) at Hanford. The Hanford Site currently has several tanks filled with PFP wastes, with each tank containing approximately one million gallons. Other DOE waste streams are also candidates for separation with the MACS process, and its use for polishing stages of cleanup operations will be evaluated in this report.

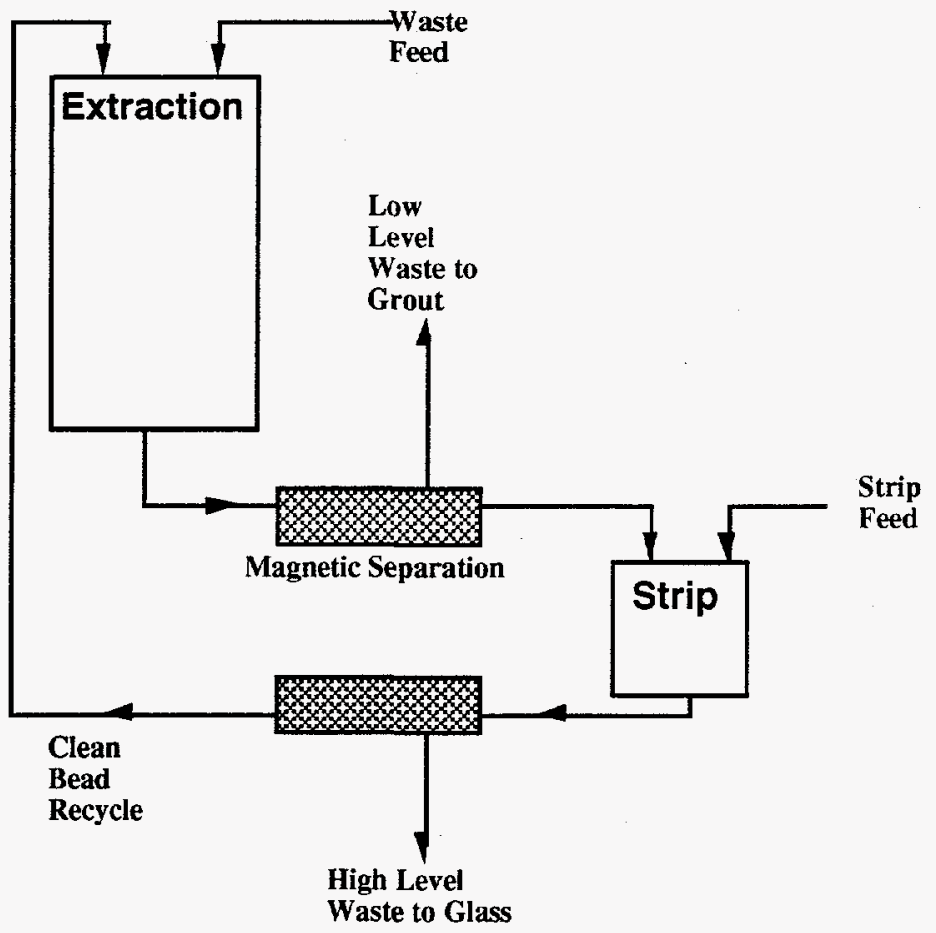

Fig. II-1. Concept Diagram of MACS Process 


\section{SYSTEM DESIGN}

The preliminary design for the MACS process includes a fluidized bed that will be used to bring ferromagnetic particles, coated with organophosphorous extractants, into contact with actinide radioisotopes in solution. Magnetically stabilized fluidized beds have been designed for chromatographic separations [DUPRE, BURNS]. In these designs, the stabilizing particles are magnetic and move with essentially plug motion across the stream to be separated. The particles may contain a solid ion-exchange medium or be coated with liquid sorbents. The MACS process could implement some of these ideas for extraction and separation of actinides. Design of a magnetically fluidized bed for the MACS process was based on the premise that an actinide separation process should operate in a compact modular unit with minimal mechanical features, so as to reduce maintenance.

Figure III-1 shows a magnetically fluidized bed with a hold-up volume of ten liters, designed for laboratory studies. The bed operates in a countercurrent fashion. A simulated waste solution enters the column from the bottom and a particle suspension is poured into the top. The particles move continuously down through the aqueous waste solution by gravity, assisted by magnetic pulsing, which promotes mixing. Pumping the waste solution up into the column also

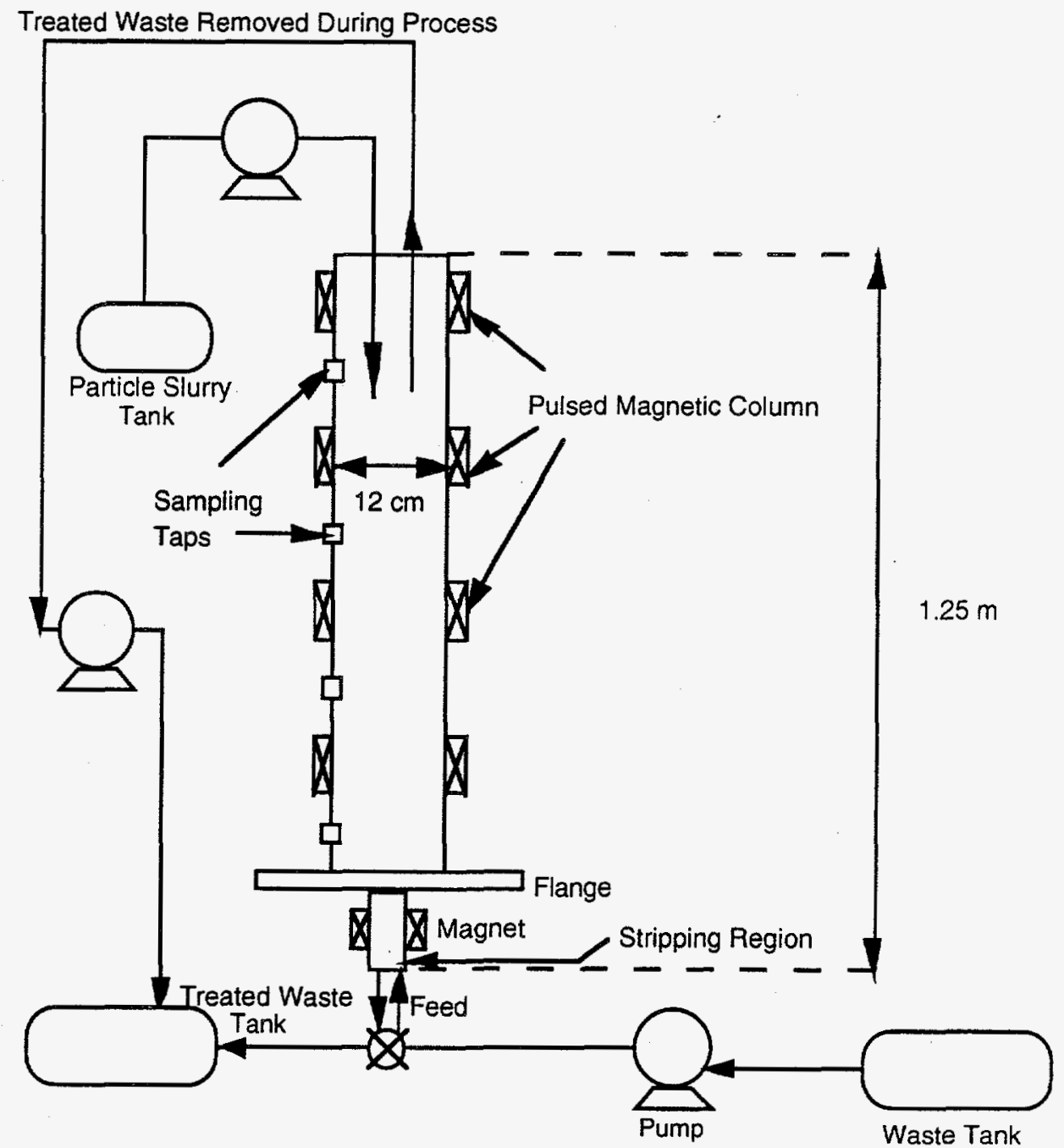

Fig. III-1. Process Diagram for MACS Fluidized Bed 
serves to disperse and fluidize the MACS particles. As the waste fluid flow increases, the upward forces of drag and buoyancy balance the downward force of gravity on the particles, and the continuous magnetic pulsing ensures complete dispersion of the particles. Pulsing is achieved by magnetic coils placed around the outside of the column on a slant, so that the particles move along the magnetic lines of force. The coils can be alternately activated and deactivated to provide vertical motion of the particles. (This concept contrasts with that for solvent extraction pulse columns, where the heavier and lighter phases of the mixture collect on contact mesh plates. A fluid pulse forces the phases into contact by pushing one through the mesh into contact with the other phase.)

The actinide elements are extracted from the solution by the CMPO/TBP adsorbed on the magnetic particles, and decontaminated waste is removed from the top of the column. After adequate contact time, or when the supply of waste is depleted, the particles are allowed to settle to the stripping region at the bottom of the column, separated from the remaining waste solution by a magnet, and sent through a stripping process to remove the activity. The particles can then be recycled for use in further extractions.

The Ergun equation (Eq. III-1) can be used to solve for various quantities related to packed and fluidized beds. The equation has two separate terms: the first accounts mostly for laminar flow characteristics while the second accounts for those resulting from turbulence [McCABE]. For the MACS process, the small size $(<25 \mu \mathrm{m})$ of the particles means that only laminar flow characteristics are important (Stokes' Law).

$$
\frac{\Delta \mathrm{P}}{\mathrm{l}}=\frac{150 \mu \mathrm{Vom}_{\mathrm{m}}}{\mathrm{Dp}^{2}} \frac{(1-\varepsilon)^{2}}{\varepsilon^{3}}+\frac{175 \rho \mathrm{Vom}^{2}}{\mathrm{Dp}} \frac{(1-\varepsilon)}{\varepsilon^{3}}
$$

where

$$
\begin{aligned}
\Delta \mathrm{P} & =\text { pressure drop, } \mathrm{Pa} \\
1 & =\text { bed height, } \mathrm{m} \\
\mu & =\text { viscosity, } \mathrm{kg} / \mathrm{m} \cdot \mathrm{sec} \\
\text { Vom } & =\text { minimum fluidization velocity, } \mathrm{m} / \mathrm{sec} \\
\mathrm{D}_{\mathrm{p}} & =\text { particle diameter, } \mathrm{m} \\
\varepsilon & =\text { void fraction of the bed (dimensionless) } \\
\rho & =\text { density of the fluid in the bed, } \mathrm{kg} / \mathrm{m}^{3}
\end{aligned}
$$

In the design of the MACS system, the minimum fluidization velocity was calculated based on assumed values for particle diameter $(1-25 \mu \mathrm{m})$ and density $\left(2.5-5.0 \mathrm{~g} / \mathrm{cm}^{3}\right)$, void fraction $(0.1-0.9)$, and waste stream viscosity and density (approximately equal to that of water). The pressure drop and bed height were calculated based on reasonable values for particle diameter and density. For a typical waste stream, the calculated pressure drop ranged from $2.14 \times 10^{-1}$ to $5.69 \times 10^{-1}$ psi for a bed height of $1.7 \times 10^{-3}$ to $3.5 \times 10^{-3} \mathrm{~m}$, based solely on the density of particles at rest. The bed height during fluidization will increase with flowrate until the particles are extracted in the fluid and remain at the top of the column. Until further experiments are done to find the void fraction at high flowrates, the bed height can only be estimated up to approximately $50 \mathrm{~cm}$. 


\section{PREPARATION AND OPTIMIZATION OF TRU REMOVAL PARTICLES}

\section{A. Particle Selection Based on Morphology Studies and Magnetite Distribution}

\section{1. $\quad$ Particle Testing}

Five commercially available magnetic particles (Table IV-1) were tested for use in the MACS process. Chemical details are given in APPENDIX A. The following sections describe the measurements we made on these particles.

\section{a. Microscopy and Energy Dispersive Spectroscopy (EDS)}

Particle morphology, including resin effects on the particles, was examined by using transmission electron microscopy (TEM) and/or energy dispersive spectroscopy (EDS). Samples were prepared for TEM by ultramicrotomy. First, a polyethylene BEEM ${ }^{\mathrm{TM}}$ capsule was filled with Medcast resin to a depth of approximately $1.5 \mathrm{~cm}$. The samples were sectioned to a nominal thickness of $\sim 1000 \mathrm{~nm}$ by using an ultramicrotome with a diamond knife. Sections were floated onto a bath of deionized water, then placed upon a carbon film supported by a 3-mm copper grid. Samples were examined in a JEOL 2000FXII Transmission Electron Microscope at $200 \mathrm{kV}$; the variable aperture was removed for electron diffraction measurements. Samples that were suitable for EDS analysis were examined in tandem using a NORAN ultrathin window system in the horizontal port of the JEOL 2000.

\section{b. Particle Binding Strengths and Integrity}

An important consideration for applications of MACS particles is the absorption or binding strength exhibited between (1) the magnetite core and the polymeric coating and (2) the polymeric coating and the adsorbed solvent. Loss of interfacial integrity in either case under conditions in high-level waste tanks is undesirable. Chemical durability of the magnetite core is also required. Waste streams can be highly acidic, and dissolution of the magnetite would have a similar effect to that caused by physical separation of the magnetite and polymer or the polymer and solvent.

The capacity of the particles to sorb the organophosphorous extractants and also to maintain physical integrity under chemical (acid) and physical (gamma irradiation) [NUNEZ1994A] attack was examined by using TEM. Sample beads were tested for their ability

Table IV-1. Magnetic Particles Selected for Microscopic Study

\begin{tabular}{clcc}
$\begin{array}{c}\text { Sample } \\
\text { No. }\end{array}$ & \multicolumn{1}{c}{ Description } & Size, $\mu \mathrm{m}$ & Manufacturer \\
\hline & DVBa/acrylic acid (58\%) bound to magnetite core (35\%) & 0.68 & Bang \\
1 & Magnetite particles bound to polyacrolein core & $1-10$ & Cortex \\
2 & Charcoal-coated magnetite particles & $1-25$ & Cortex \\
4 & Magnetite particles embedded in Sb/DVB & 12 & Bang \\
5 & $\begin{array}{l}\text { Acrylamide-based magnetite particles with charcoal- } \\
\text { dextran coating }\end{array}$ & 12 & BioMag \\
\hline
\end{tabular}

aDVB = divinylbenzene.

bS = styrene. 
to sorb the CMPO/TBP solvents and to separate americium from solution in $2 \mathrm{M}$ nitric acid. The measure of extraction, the partitioning coefficient, $\mathrm{K}_{\mathrm{d}}$, is determined by Eq. IV-1 [APPENDIX B].

where

$$
K_{d}=\left(\frac{C_{i}-C_{f}}{C_{f}}\right) \times \frac{V}{m}
$$

$$
\begin{aligned}
& \mathrm{V}=\text { contact volume of TRU solution, } \mathrm{mL} \\
& \mathrm{m}=\text { mass of particles, } \mathrm{g} \\
& \mathrm{C}_{\mathrm{i}}=\text { initial stock concentration of the sorbed species before contact, counts } / \mathrm{mL} \\
& \mathrm{C}_{\mathrm{f}}=\text { final solution concentration of the sorbed species after contact, counts } / \mathrm{mL}
\end{aligned}
$$

Selection of suitable particle types for MACS applications was based on the results of TEM examinations, magnetic measurements, and gamma irradiations, as well as $\mathrm{K}_{\mathrm{d}}$ determinations.

\section{2. $\quad$ Results and Discussion}

\section{a. Resin Effects, Inner-Outer Polymeric Sphere Magnetite Distribution, and $\mathrm{K}_{\mathrm{d}}$ Determinations}

In the first stage of this work, TEM sample preparation techniques were examined to determine whether samples could be produced in the absence of chemical interaction with the embedding resin used to mount them for ultramicrotomy. To provide a baseline view of the particles, samples were examined by TEM before complexation or exposure to radiation. Four of the five samples in Table IV-1 were examined by TEM. Sample 3, the charcoal-coated sample, was not used for microtomy because the particles were quite large (up to $25 \mu \mathrm{m}$ ).

Samples of each particle type (1,2, 4, and 5) were embedded in Medcast, Araldite, and LR White embedding resins. All particles sectioned well, and there was no significant difference between particles embedded in the different epoxy resins. However, magnetite crystallites were observed to be bound to the surface of particles in sample 2 and the crystallites appeared to loosen from LR White epoxy prior to curing. The TEM micrographs shown in Fig. IV-1 are of samples 1, 2, 4, and 5 embedded in Medcast or Araldite.

The TEM micrograph of the divinylbenzene-magnetite particles is shown in Fig. IV-1a. The magnetite cores were rather large $(0.2 \mu \mathrm{m})$ and irregularly shaped. The polymer appeared to be randomly bound to the surface of the core. The divinylbenzene polymer demonstrated low sorption of the CMPO/TBP solvents, with $\mathrm{K}_{\mathrm{d}} \leq 100$ for americium in $2 \mathrm{M}$ nitric acid.

The TEM micrograph of the polyacrolein-magnetite particles is shown in Fig. IV-1b. The magnetite particles were extremely small $(<1 \mathrm{~nm})$ and the magnetite was attached to the outer surface of the polymer rather than being located in the core. Two deleterious effects are likely. First, the magnetite particles may obstruct access of the organophosphorous solution to the polymer core; thus, the effective surface area of the particle will be dramatically reduced, and TRU absorption will be limited by diffusion of the extractants through the narrow spaces between the magnetite particles. Second, an exposure to radiation is likely to embrittle the polymer and may result in loss of the very small magnetite particles attached to the surface. The nonporous polyacrolein polymer demonstrated insignificant sorption of the CMPO/TBP solvents, with $\mathrm{K}_{\mathrm{d}} \leq 10$ for americium in $2 \underline{\mathrm{M}}$ nitric acid solutions. 

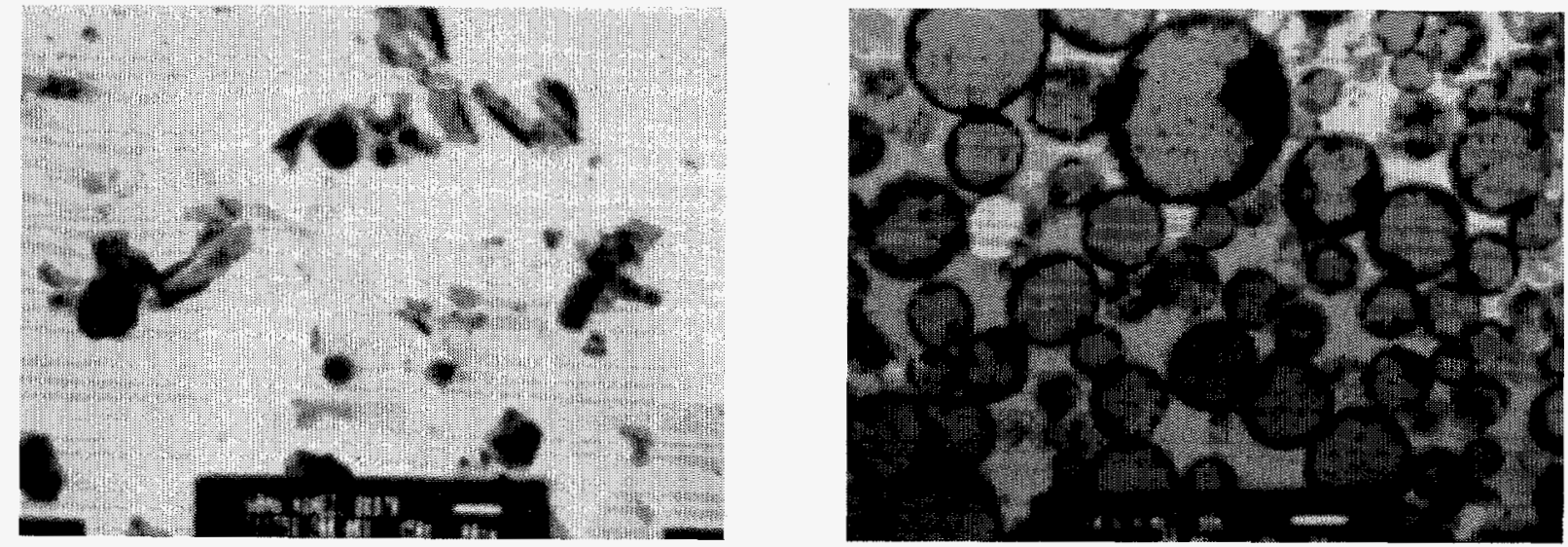

(a)

(b)
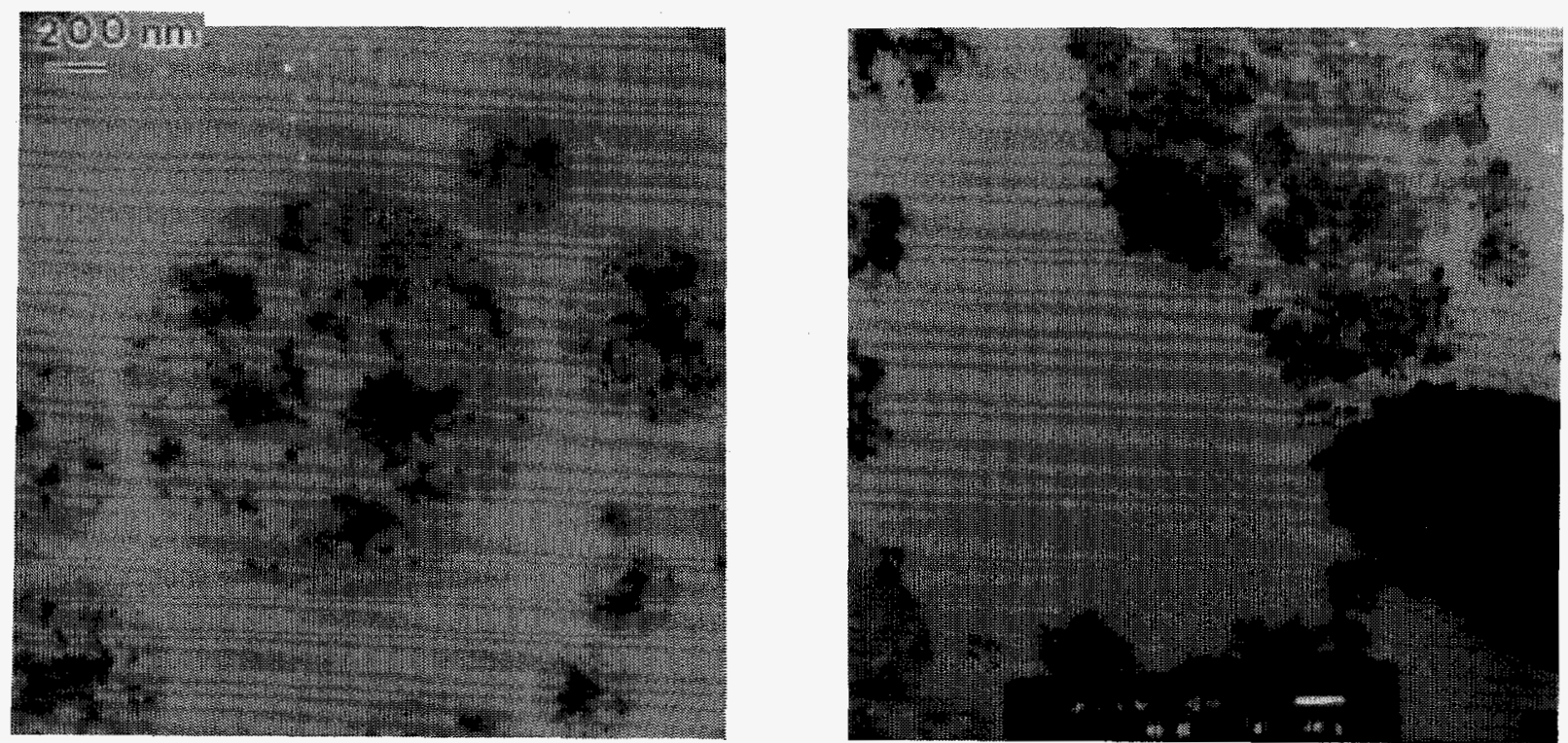

(c)

(d)

Fig. IV-1. TEM Micrographs of Magnetic Particles. (a) Divinylbenzene-magnetite particles, which are large $(0.2 \mathrm{~mm})$ irregularly-shaped particles with polymer randomly bonded to the surface core. (b) Brightfield image of polyacrolein-magnetite particles embedded in Araldite. Magnetite particles are small $(<10 \mathrm{~nm})$ and attached to the outer surface of the polymer. (c) Mag-encapsulated particles. The magnetite particles are small $(\sim 10 \mathrm{~nm})$ and are embedded as agglomerates within the polymer. (d) Dextran-coated particles. Particles are randomly shaped, with a non-uniform polymer coating. In most cases, it does not appear that the magnetite and polymer are tightly bound. 
The TEM micrograph of the styrene/divinylbenzene-magnetite particles is shown in Fig. IV-1c. The particles were uniform in shape, with magnetite particles embedded as clumps within the absorptive polymer; thus, most of the surface of these particles will be available for absorption. The styrene/divinylbenzene polymer showed low sorption of the CMPO/TBP solvent, with $\mathrm{K}_{\mathrm{d}} \leq 100$ for americium in $2 \underline{\mathrm{M}}$ nitric acid.

The TEM micrograph of the acrylamide-based magnetite particles is shown in Fig. IV-1d. The particles were randomly shaped, and the distribution of magnetite was also irregular. Some particles appeared to be a mass of magnetite, while others had very little magnetite attached. It is possible that a significant number of particles will not be magnetically separable because of the low levels of magnetite. The charcoal/dextran polymer showed low sorption of the CMPO/TBP, with $\mathrm{K}_{\mathrm{d}} \leq 100$ for americium in $2 \mathrm{M}$ nitric acid solution.

In contrast to particles $1,2,4$, and 5 , the polymer combination of charcoal in a cross-linked $\mathrm{N}, \mathrm{N}$-methylene bis-acrylamide gave $\mathrm{K}_{\mathbf{d}} \geq 4000$ for an americium tracer solution in $2 \mathrm{M}$ nitric acid. This high partition coefficient was attributed to the chemical affinity of the polymer and the large surface area of the particles.

\section{b. Magnetic Properties}

Magnetic properties of superparamagnetic particles with and without extractant coating, and gamma irradiation effects, will be discussed in a future report of the MACS process by B. A. Buchholz.

\section{B. Adsorbent Solvent Selection}

Argonne is developing a magnetic particle coated with CMPO (Fig. IV-2), the solvent currently used in the TRUEX process [VANDEGRIFT-1993].

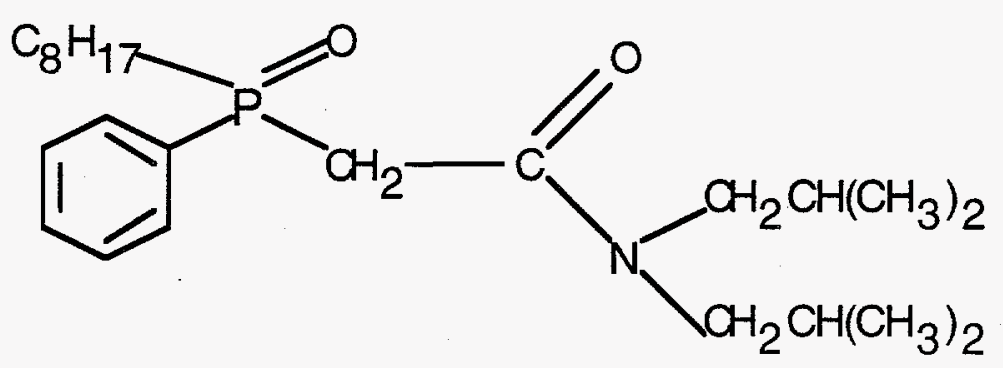

Fig. IV-2. Structure of CMPO $(\mathrm{MW}=419 \mathrm{~g} / \mathrm{mol})$

The extensive experience in the development of the TRUEX process and related solvent extraction processes led us to the selection of CMPO/TBP as the solvent for the MACS process [VANDEGRIFT-1984]. A CMPO-based solvent is a natural choice for the MACS process because of CMPO's high selectivity and extracting power for actinides and its ability to be adsorbed onto a solid particle [HORWITZ-B]. (Elchrom has used a CMPO solvent to prepare commercial chromatographic material).

To make the MACS process as effective as possible, distribution ratios and solvent loading of TRU elements should be high, but mass transport should not limit the effectiveness of separation. The composition of the solvent coating needs to be optimized to achieve these two frequently opposing objectives. Increasing the concentration of CMPO will increase distribution ratios and loading; however, it is also likely to increase the solvent's viscosity and its propensity to separate into two phases, thus lowering mass transfer. As in the standard TRUEX solvent, 1.4M TBP in a normal paraffinic hydrocarbon (NPH) diluent will be used as a solvent modifier [SCHULZ]. 
Complexes of CMPO and TBP with americium and plutonium have been modeled for the TRUEX composition (0.2M CMPO, 1.4M TBP in NPH) by the Generic TRUEX model (GTM) [VANDEGRIFT-1990, VANDEGRIFT-1993] . The GTM uses thermodynamic solution properties and aqueous activity coefficients to model chemical equilibria in the aqueous and nonaqueous phase. The magnetic particles tested have larger $\mathrm{K}_{\mathrm{d}}$ values than those predicted by distribution ratios in traditional liquid/liquid extraction systems. This illustrates one advantage of the MACS process over traditional separation methods.

\section{Optimization of Extractant Adsorption}

\section{Coating Procedure}

The most promising polymeric coating for CMPO/TBP adsorption was charcoal in a cross-linked N,N'-methylenebisacrylamide (see Sect. IV-A). The particles owe their superparamagnetic properties to magnetite, incorporated in their structure. They vary in size from 0.1 to $25 \mu \mathrm{m}$, and possess a wide range of shapes. For CMPO/TBP adsorption, the particles were washed with $0.02-\mu \mathrm{m}$ filtered water several times to eliminate preservatives and additives, then dried and weighed. Then, $0.02-\mu \mathrm{m}$ filtered hexane or ethanol was used to disperse the particles and act as a volatile diluent for the coating. The CMPO/TBP solvent was added to the mixture, and the particles were dispersed in an ultrasonic bath, dried in a rotoevaporator at $80-100^{\circ} \mathrm{C}$, and finally annealed in an oven at $100-150^{\circ} \mathrm{C}$ for several hours until constant weight was obtained.

\section{Annealing of Sorption Coatings}

In the initial stage of development, coating of the particles showed inhomogeneity within a single particle batch. The parameters governing particle coating were investigated. Various experiments were performed to determine the sensitivity of the preparation process to systematic variation of physical variables (e.g., temperature, volume) and the effect of changing the volatile liquid volume [APPENDIX C]. Further discussion of coating is presented in Section IV-E.

\section{Nitric Acid Effects on Partitioning of TRU Elements}

The effect of nitric acid on the MACS process is important for the application of this process to waste streams having a wide range of acidities. Dissolution of solid or sludge waste is usually achieved by addition of nitric acid, and the chemical stability of the TRU elements in acid solutions is well documented [CLEVELAND, MORSS].

\section{Experimental Procedure}

Partitioning experiments were performed with particle suspensions $(\leq 1 \mathrm{wt} \%)$ in nitric acid and simulant solutions containing ${ }^{241} \mathrm{Am}$ or $238 \mathrm{Pu}$. This low ratio of particle mass-to-solution volume allows comparison with more traditional separation techniques such as solvent extraction and ion exchange. The suspensions were held in a sonic cleaning bath to enhance the dispersion, then placed in a bath at $25^{\circ} \mathrm{C}$ to attain thermal equilibrium, and agitated with a vortex mixer to further disperse the solid suspension. The temperature bath and vortex steps were repeated twice, then the mixtures were centrifuged and placed in a rare-earth permanent magnet rack to separate the particles. The supernatant was withdrawn from solution, and an aliquot was used for liquid scintillation $\left({ }^{238} \mathrm{Pu}\right)$ or gamma $\left({ }^{241} \mathrm{Am}\right)$ counting. Equation $\mathrm{NV}-1$ was used to calculate $\mathrm{K}_{\mathrm{d}}$ values.

\section{2. $\quad$ Results and Discussion}

The partition coefficients for different concentrations of nitric acid were monitored using ${ }^{241} \mathrm{Am}$ and ${ }^{238} \mathrm{Pu}$ tracers. Measurements were made in $0.001,0.01,0.1,2,5$, and $8 \mathrm{M} \mathrm{HNO}_{3}$ with 1M CMPO diluted in TBP. The results, presented in Fig. IV-3, were similar for the two isotopes. The $\mathrm{K}_{\mathrm{d}}$ values for americium and plutonium increased slowly with increasing $\mathrm{HNO}_{3}$ concentration, reaching peaks at $2 \underline{\mathrm{M}}$ and $5 \underline{\mathrm{M}} \mathrm{HNO}_{3}$, respectively. These results suggest that the process can be applied in a batch mode for a wide range of high nitric acid concentrations without a large loss in extraction capabilities. 
The volume of solvent (extractant) absorbed on the surface of the particle can be estimated using the solvent coverage fraction, $\theta$ (Eq. IV-2), which allows the $K_{d}$ value to be transformed into the more traditional distribution ratio, $D$ (see Appendix $C$ ).

$$
\theta=\frac{\text { wt of extractant }}{\text { wt of particles }}
$$

First, the ratio, f, of particle weight (g) to solvent volume (mL) (Eq. IV-3), can be determined from the volume of solvent added to a known weight of particles in the coating process, and the density of the solvent $\left(\rho_{\text {ext }}\right)$.

$$
f=\frac{\text { wt of particles }}{\text { vol of extractant }}=\frac{1}{\theta} \times \rho_{\text {ext }}
$$

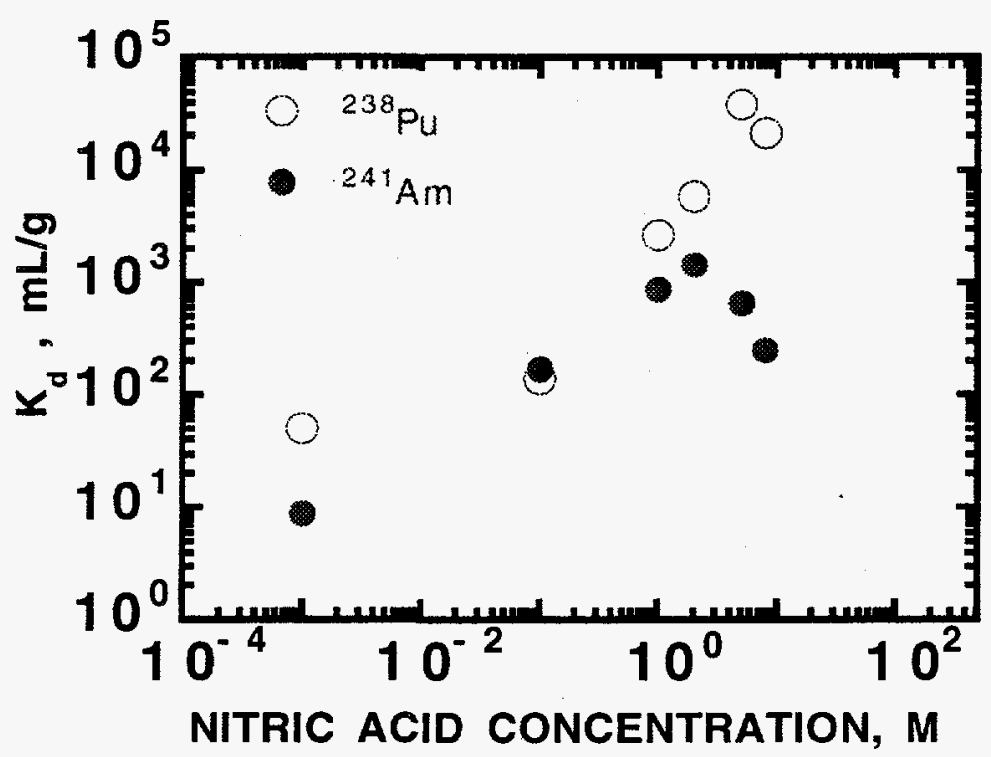

Fig. IV-3. $\mathrm{K}_{\mathrm{d}}$ vs. Nitric Acid Concentration for ${ }^{241} \mathrm{Am}$ and ${ }^{238} \mathrm{Pu}$ for $1.0 \mathrm{M}$ CMPO/TBP Coatings on Magnetic Particles at $25^{\circ} \mathrm{C}$ 
Since the weight in the $K_{d}$ term (see Eq. IV-5) is a total $\left(m_{t}=\right.$ weight of particle + weight of extractant) it must be converted to weight of particle $\left(m_{p}\right)$ by using $\theta$ (Eq. IV-4).

$$
\mathrm{m}_{\mathrm{t}}=(1+\theta) \mathrm{m}_{\mathrm{p}}
$$

Thus, $\quad \mathrm{K}_{\mathrm{d}}=\frac{\mathrm{V}_{\mathrm{aq}}}{\mathrm{m}_{\mathrm{t}}}=\frac{\mathrm{V}_{\mathrm{aq}}}{\mathrm{m}_{\mathrm{p}}}\left(\frac{1}{1+\theta}\right)$

Then $K_{d}$ is converted into a distribution ratio by using $f(E q . I V-5)$.

$$
K_{d} \times f=D \text { or } \frac{V_{a q}}{m_{p}}\left(\frac{1}{1+\theta}\right) f=D
$$

The volume occupied by the solvent and particles was previously reported [NUNEZ1994B]. The density of the particles is assumed to be in the range of $2.5-2.7 \mathrm{~g} / \mathrm{cm}^{3}$ (mainly due to the presence of $\mathrm{Fe}_{3} \mathrm{O}_{4}$ ). The value of $f$ can vary from 5 to 20 .

The americium and plutonium distribution ratios using magnetic particles were higher than those for solvent extraction and those found for CMPO absorbed onto silica particles [PIETRELLI]. The higher than expected distribution ratio may be the result of a synergism between CMPO/TBP and the charcoal/polymeric coating on the particle. Although CMPO/TBP systems have been extensively investigated, the current studies without a standard diluent are unique. Further studies are necessary to determine the precise mechanism driving the extraction. The MACS process shows promise for more efficient use of the standard organophosphorous extractants, such as CMPO and TBP, for TRU separation applications.

\section{E. Dependency of TRU Separation on Solvent Coating Thickness and Composition}

To determine the effectiveness of the particles for TRU separation, $K_{d}$ was determined for various CMPO/TBP concentrations using $2 \mathrm{M} \mathrm{HNO}_{3}$ with ${ }^{241} \mathrm{Am}$ tracer. The concentration of CMPO was varied between 1 and $1.5 \mathrm{M}$ and each concentration was tested with three different solvent volumes. A theoretical solvent coating thickness was calculated as described below.

The total number of particles was calculated from their weight. This value was multiplied by the volume of extractant needed to coat one particle, to obtain the total coating volume. A few assumptions were made to facilitate this calculation. The particles were assumed to be perfectly spherical with a diameter of $9 \mu \mathrm{m}$. The value of $9 \mu \mathrm{m}$ was chosen because it is the mean of the Gaussian distribution that was found (manufacturing company) to describe the particles. The other assumptions were that the density of the particles was $2.5 \mathrm{~g} / \mathrm{cm}^{3}$, and the coating thickness, $2 \mu \mathrm{m}$. The reported composition of the particles is 1:1:1 of polyacrylamide, charcoal, and iron oxide. For example, the initial weight of particles used was $0.4900 \mathrm{~g}$. Using the assumed values, the coating volume (V) was calculated based on a $2-\mu \mathrm{m}$ coating as follows (Eqs. IV-6 through IV-8):

$$
\begin{gathered}
\text { particle mass }=1.25 \mathrm{~g} / \mathrm{cm}^{3} \times \frac{4}{3} \pi\left(4.5 \times 10^{-4} \mathrm{~cm}\right)^{3}=9.5 \times 10^{-10} \mathrm{~g} \\
\text { number of particles }=\frac{0.49 \mathrm{~g}}{9.5 \times 10^{10} \mathrm{~g} / \text { particle }}=5.1 \times 10^{8} \text { particles } \\
\mathrm{V}_{\text {coating }}=\frac{3}{4} \pi\left[\left(4.5 \times 10^{-4} \mathrm{~cm}+2.0 \times 10^{-4} \mathrm{~cm}\right)^{3}-\left(4.5 \times 10^{-4} \mathrm{~cm}\right)^{-3}\right] \times 5.1 \times 10^{8} \text { particles }=0.39 \mathrm{~cm}^{3}
\end{gathered}
$$

The measured partition coefficients $\left(\mathrm{K}_{\mathrm{d}}\right)$ are presented in Table IV-2. For the tests illustrated in Table IV-2, the O/A ratio (volume of solvent on the particles divided by aqueous-phase 
volume) varied between 0.01 and 0.005 . This is less than the minimum O/A ratio $(0.01)$ demonstrated for solvent extraction systems using centrifugal contactors [LEONARD]. The preparation procedure used a solvent loading value $<1 \mathrm{~mL} / \mathrm{g}$.

The 1.0 and 1.5 $\underline{M}$ CMPO samples were prepared in hexane, while the $1.36 \underline{\mathrm{M}}$ CMPO samples were coated by using ethanol as the carrier diluent. Figure IV-4 illustrates the variation of $\mathrm{K}_{\mathrm{d}}$ as a function of coating thickness for various CMPO concentrations. Both the 1.0 and $1.36 \mathrm{M}$ data sets follow the expected trend of increasing $K_{d}$ with increasing coating thickness. The trend shows that, as the concentration of CMPO increases, the change in $\mathrm{K}_{\mathrm{d}}$ as a function of coating thickness decreases. For a CMPO concentration of $1.5 \underline{\mathrm{M}}$, the curve reaches a plateau. Further increases in coating thickness are limited by particle adsorption capacity.

Since the volatile solvent should have completely evaporated during the coating process, $\mathrm{K}_{\mathrm{d}}$ values should be independent of the solvent used. A comparison of the data shows that the $K_{d}$ values for the $1.36 \mathrm{M}$ CMPO with ethanol fall outside the range observed for the 1.5 and 1.0M CMPO with hexane (Fig. IV-4). On the basis of annealing experiments [APPENDIX C], this discrepancy may be due to differences in the $1.36 \mathrm{M}$ coating process. Figure IV-4 also reflects that saturation occurs within a small coating solvent thickness range for most CMPO concentrations.

\section{F. Effect of Temperature on TRU Extraction}

The extraction of americium by $1 \mathrm{M}$ CMPO/TBP as a function of nitric acid concentration was monitored at three temperatures $\left(10^{\circ}, 25^{\circ}\right.$, and $\left.50^{\circ} \mathrm{C}\right)$. Figure $\mathrm{IV}-5$ illustrates the results.

Table IV-2. Dependency of $K_{d}$ on Coating Thickness and Composition

\begin{tabular}{ccccc}
\hline $\begin{array}{c}\text { Solvent } \\
\text { Loading, } \\
\mathrm{mL} / \mathrm{g}\end{array}$ & $\begin{array}{c}\text { CMPO } \\
(\mathrm{M})\end{array}$ & $\begin{array}{c}\text { Thickness, } \\
\mu \mathrm{m}\end{array}$ & $\begin{array}{c}\mathrm{K}_{\mathrm{d}}, \\
\mathrm{mL} / \mathrm{g}\end{array}$ & $\begin{array}{c}\text { O/A } \\
\text { Ratios }\end{array}$ \\
\hline $1.01 \mathrm{E}-01$ & 1 & 0.6 & 827 & $4.61 \mathrm{E}-03$ \\
$1.41 \mathrm{E}-01$ & 1 & 0.8 & 1395 & $6.42 \mathrm{E}-03$ \\
$1.84 \mathrm{E}-01$ & 1 & 1 & 2471 & $8.36 \mathrm{E}-03$ \\
$1.84 \mathrm{E}-01$ & 1.36 & 1 & 497 & $8.36 \mathrm{E}-03$ \\
$2.30 \mathrm{E}-01$ & 1.36 & 1.2 & 856 & $1.05 \mathrm{E}-02$ \\
$2.80 \mathrm{E}-01$ & 1.36 & 1.4 & 1096 & $1.27 \mathrm{E}-02$ \\
$7.39 \mathrm{E}-02$ & 1.5 & 0.45 & 2832 & $3.35 \mathrm{E}-03$ \\
$9.41 \mathrm{E}-02$ & 1.5 & 0.56 & 2401 & $4.27 \mathrm{E}-03$ \\
$1.11 \mathrm{E}-02$ & 1.5 & 0.65 & 2660 & $5.05 \mathrm{E}-03$ \\
\hline
\end{tabular}

avolume of organic phase extractant/mass of particles.

bVolume of solvent on particles/volume of aqueous phase. 


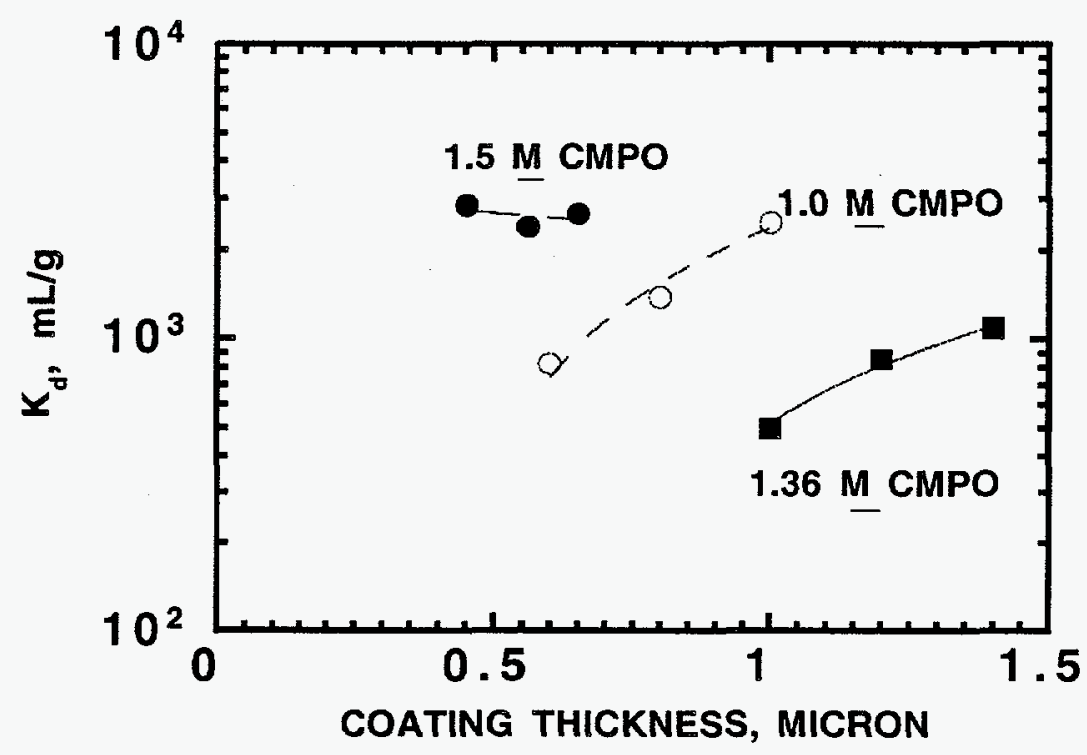

Fig. IV-4. Plot of Dependence of $\mathrm{K}_{\mathrm{d}}$ on Calculated Coating Thickness for ${ }^{241} \mathrm{Am}$

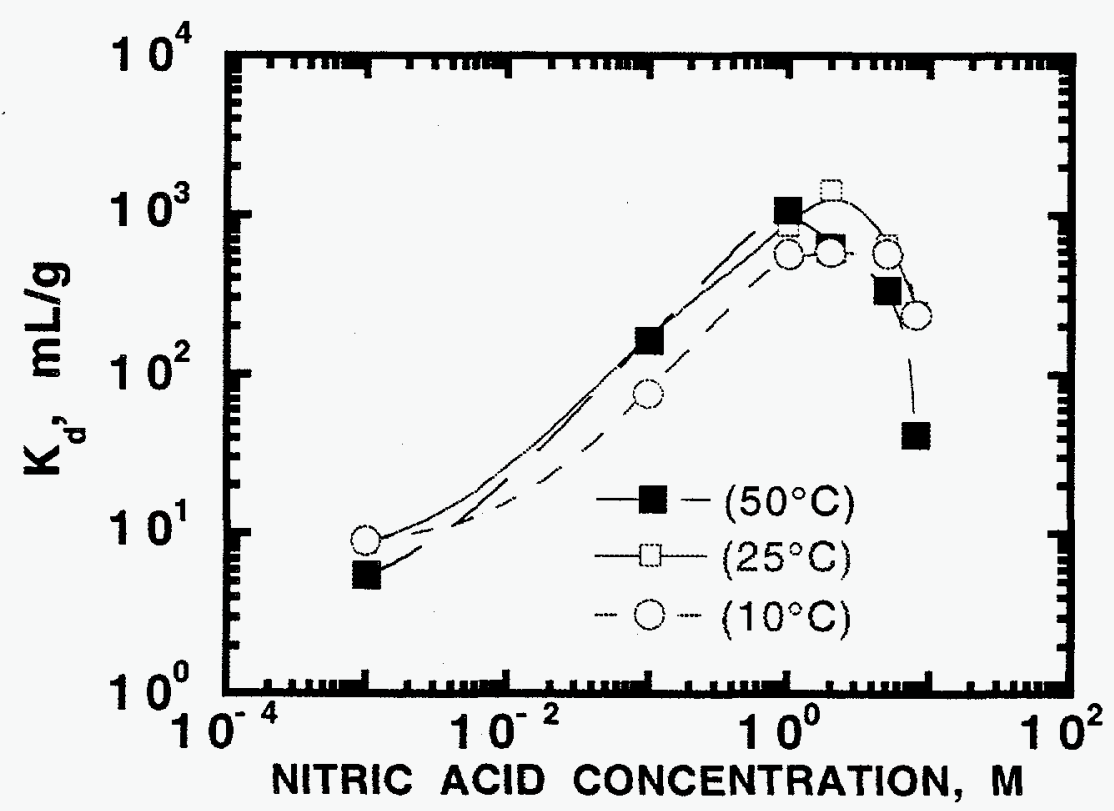

Fig. IV-5. The $\mathrm{K}_{\mathrm{d}}$ Values for Americium for $1 \mathrm{M}$ CMPO/TBP vs. Nitric Acid Concentration at $10^{\circ}, 25^{\circ}$, and $50^{\circ} \mathrm{C}$ 
All three $\mathrm{K}_{\mathrm{d}}$-vs.-nitric acid curves $\left(10^{\circ}, 25^{\circ}\right.$, and $\left.50^{\circ} \mathrm{C}\right)$ had the same general shape. In many solvent extraction systems, the distribution ratios of the metals decrease with increasing temperature [RYDBERG]. The $K_{d}$ values for the americium extraction using the MACS particles showed negligible temperature dependency between 10 and $50^{\circ} \mathrm{C}$.

\section{G. Loading Effects}

The major limitation for most countercurrent solvent extraction processes is the loading of the extractant or solvent with competing complexation species. In practice, the limit of a multistage or batch process depends on the solvent's loading capabilities.

\section{Experiments}

The loading capacity of a sample of coated particles was investigated using europium as a TRU analog. This cold test with europium contacted a sample of particles with successive fresh solutions of a simulated single-shell tank (SST) dissolved sludge (see Table IV-3). A sample of particles coated with $0.75 \mathrm{M}$ CMPO/TBP was mixed with $5 \mathrm{~mL}$ of a simulant solution. The mixture was contacted by the extraction procedure as described previously and the supernatant was completely removed at the end of the magnetic separation. Then, $5 \mathrm{~mL}$ of a fresh simulant solution was added and a new stage was initiated. Each individual extraction was considered to be a process stage. After seven stages were completed, the samples were prepared for neutron activation analysis (NAA) (APPENDIX D). The simulated SST dissolved sludge had an initial europium concentration of $1470 \mu \mathrm{g} / \mathrm{mL}$ when analyzed by inductively coupled plasma (ICP) spectroscopy.

The NAA was conducted at the University of Illinois. The concentration of europium was measured using the $841.6-\mathrm{keV} \gamma$ ray from the decay of the metastable state of ${ }^{152} \mathrm{Eu}$ with a 9.29-hour half-life (Eq. IV-9). This $\gamma$ ray was selected because the background is

Table IV-3. SST Dissolved Sludge Simulant Composition

\begin{tabular}{cc}
\hline \multicolumn{2}{c}{ SST Dissolved Sludge } \\
\hline Ionic Species & Concentration, $\underline{\underline{\mathrm{M}}}$ \\
\hline $\mathrm{H}^{+}$ & $3.40 \mathrm{E}+00$ \\
$\mathrm{Ag}^{+}$ & $5.60 \mathrm{E}-03$ \\
$\mathrm{Ba}^{2+}$ & $5.30 \mathrm{E}-03$ \\
$\mathrm{Bi}^{3+}$ & $1.80 \mathrm{E}-02$ \\
$\mathrm{Ca}^{2+}$ & $4.90 \mathrm{E}-02$ \\
$\mathrm{Cd}^{2+}$ & $5.90 \mathrm{E}-04$ \\
$\mathrm{Cr}^{3+}$ & $3.80 \mathrm{E}-02$ \\
$\mathrm{Co}^{2+}$ & $7.20 \mathrm{E}-04$ \\
$\mathrm{Eu}^{3+}$ & $9.70 \mathrm{E}-03$ \\
$\mathrm{Fe}^{3+}$ & $1.70 \mathrm{E}-01$ \\
$\mathrm{Mg}^{2+}$ & $1.60 \mathrm{E}-03$ \\
$\mathrm{Mn}^{2+}$ & $4.30 \mathrm{E}-02$ \\
$\mathrm{Na}^{+}$ & $7.10 \mathrm{E}-02$ \\
$\mathrm{~Pb}^{2+}$ & $6.50 \mathrm{E}-03$ \\
$\mathrm{Zn}^{2+}$ & $2.50 \mathrm{E}-03$ \\
$\mathrm{Zr}^{4+}$ & $1.20 \mathrm{E}-02$ \\
$\mathrm{NO}_{3}{ }^{-}$ & $4.43 \mathrm{E}+00$ \\
\hline
\end{tabular}


relatively level in this energy range. The large neutron capture cross-section of ${ }^{151}$ Eu permitted a short (five minute) irradiation. The samples were allowed to decay for approximately 27 hours before counting so that the shorter-lived states, ${ }^{152} \mathrm{Eu}$ and ${ }^{154} \mathrm{Eu}$, would decay.

$$
{ }^{151} \mathrm{Eu}+\mathrm{n} \rightarrow{ }^{152 \mathrm{~m}} \mathrm{Eu}+\gamma
$$

\section{2. $\quad$ Results and Discussion}

\section{a. Neutron Activation}

The concentration of europium in the successive contact solutions asymptotically approached the concentration in the stock solution (see Fig. IV-6). An empirical equation describes the asymptote where the europium concentration is a function of the loading stage number L (Eq. IV-10).

$$
[\mathrm{Eu}]=1470 \times[1-\exp (-a \times \mathrm{L})]
$$

The constant $a$ can be viewed as a loading parameter. A large value of $a$ means that the concentration of successive contact solutions rapidly approaches the stock solution concentration, indicating that the particles are quickly saturated with the loading substance. If the loading parameter is small, the concentration of the loading material slowly approaches the stock solution concentration, indicating a large capacity of the particles for removal of the loading material.

In the experimental case, the europium concentration changed little after the second contact with the SST simulant. Figure IV-6 shows measured values of europium concentration vs. loading stage and the theoretical curve produced if the loading parameter $a$ is unity. Although the experimental points show significant scatter because of the mass balance assumptions (with no carryover of supernatant), the general trend indicates that the particles did not reach complete saturation after seven loading stages. Further work with high ionic strength

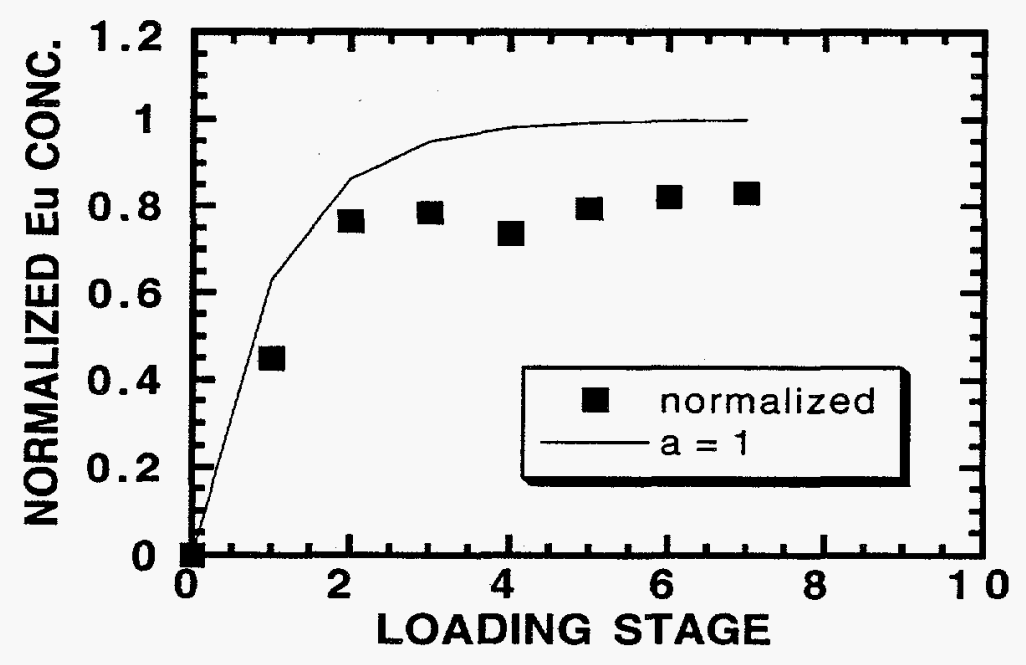

Fig. IV-6. Distribution of Europium as a Function of Loading Stage. The squares are the experimental points normalized to total Eu concentration and the line is for $a=1$. 
nitrate salts at low acidities is required to increase the loading and improve the statistics [ANDERSON].

\section{b. Microscopy and EDS}

Micrographs were taken of charcoal-coated material and of the particles contacted with a $\mathrm{Nd}\left(\mathrm{NO}_{3}\right)_{3} / \mathrm{NaNO}_{3}$ solution to observe neodymium (analog for actinides) loading. The micrographs (Fig. IV-7) of charcoal particles illustrate (1) the irregular shapes that provide large surface areas for CMPO/TBP absorption/complexation and (2) the absence of magnetite in some of the charcoal particles contacted with PFP simulant (see Sect. V.A) waste solution. Images of the particles show that the charcoal coating is nonuniform. In fact, some particles appear to be composed entirely of charcoal (see Fig. IV-7).

The particles loaded with neodymium were studied by both TEM and EDS. The EDS analysis revealed no clustering or accumulation of neodymium for regions greater than 25 $\AA$ (resolution of the diffraction technique). Images of the particles complexed with neodymium were essentially the same as those of the uncomplexed particles (Fig. IV-8); charcoal particles varied in size and did not encompass the magnetite "cores." Well-crystallized materials were only observed in the magnetite "cores." The EDS spectra indicated that low levels of neodymium were homogeneously distributed in the amorphous charcoal regions. There were no regions of highly concentrated neodymium. Both surface and bulk regions of the charcoal particles were examined, with no striking differences found between the two regions (Fig. IV-9).

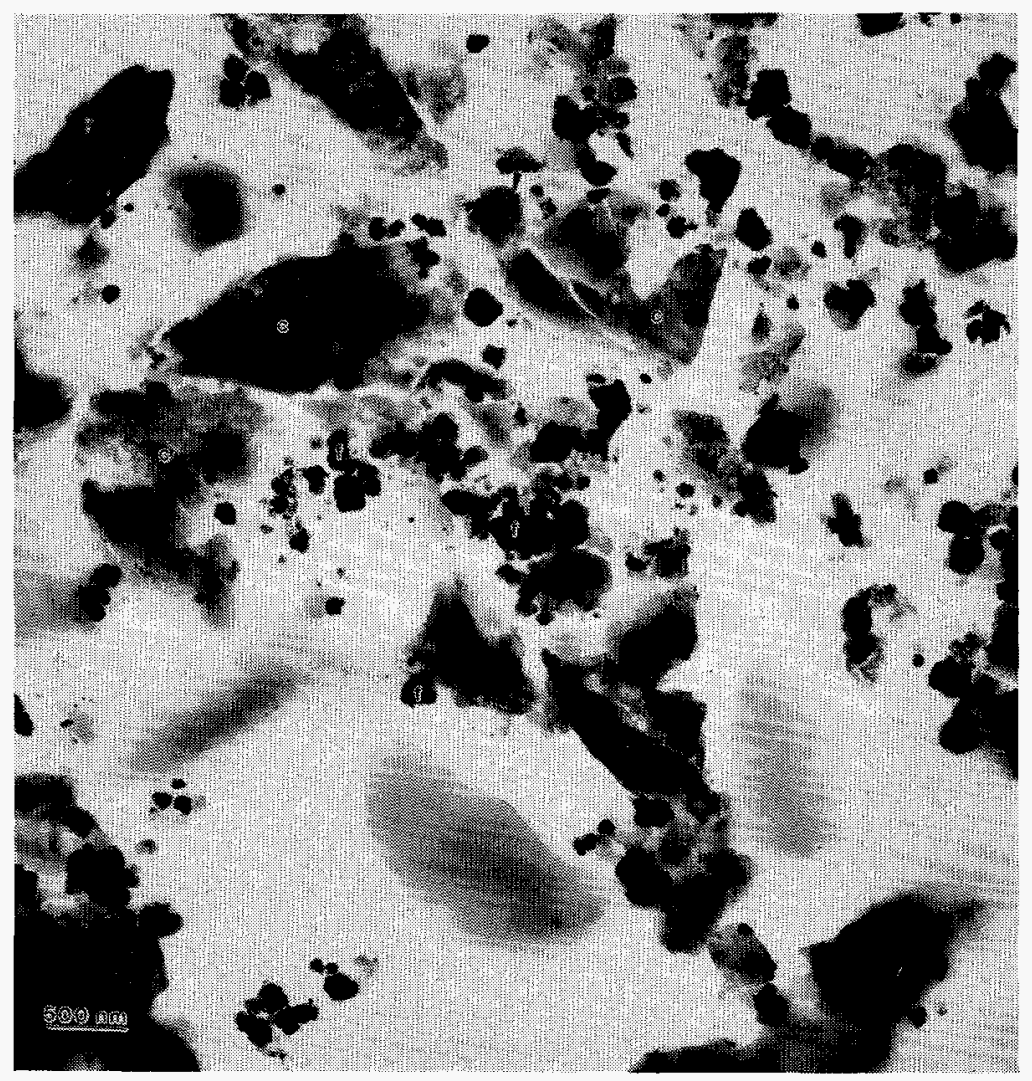

Fig. IV-7. Low Magnification View of Charcoal Particles (c) and Associated Magnetite Particles (f). Not All Particles are Labeled. Charcoal particles vary in size and do not encompass the magnetite "cores." 


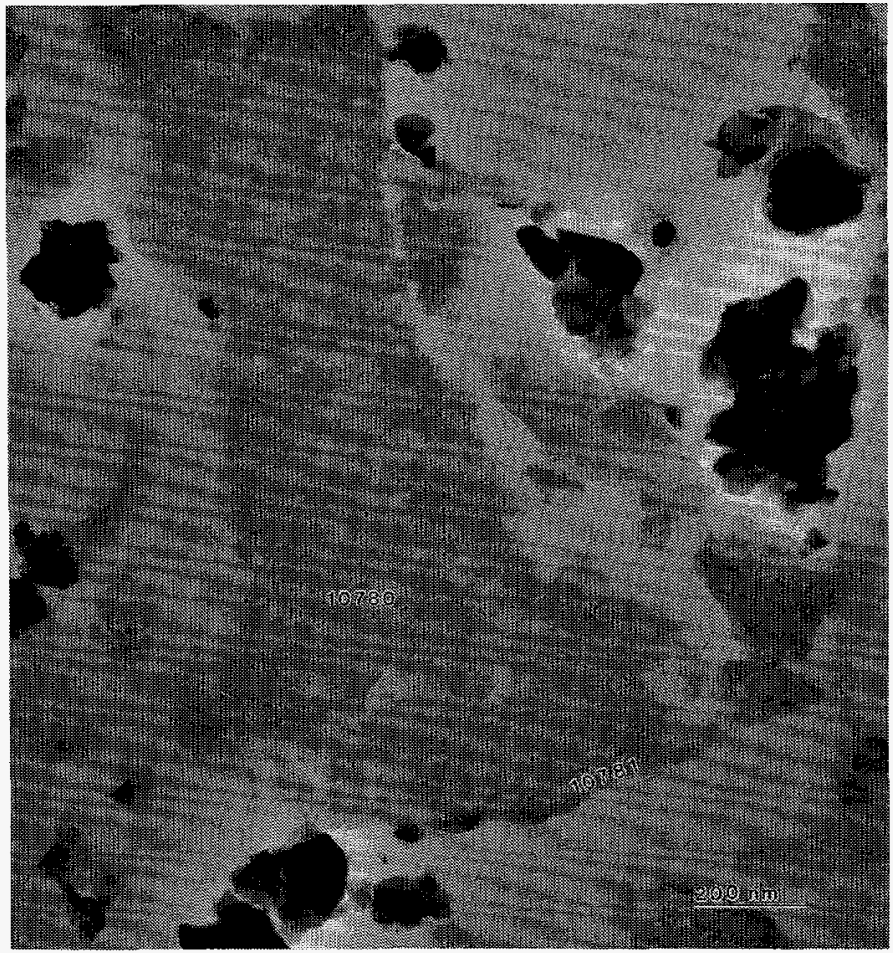

Fig. IV-8. A Neodymium-Complexed Charcoal Particle. The locations of EDS spectra 10780 (interior) and 10781 (surface) are indicated (See Fig. IV-9).

The EDS spectra also indicated the presence of other elements (e.g., $\mathrm{Cu}, \mathrm{Si}$ ). This is probably an artifact; HF leaches Si from glass tubes. The neodymium $\alpha, \beta$, and $L \beta_{2}$ lines are at $5.229,5.727$, and $6.088 \mathrm{keV}$, respectively. The instrument artifact lines of copper $\alpha_{1}$ and $\alpha_{2}$ are at 8.041 and $8.904 \mathrm{keV}$, respectively and a silicon line was observed at $1.739 \mathrm{keV}$. 

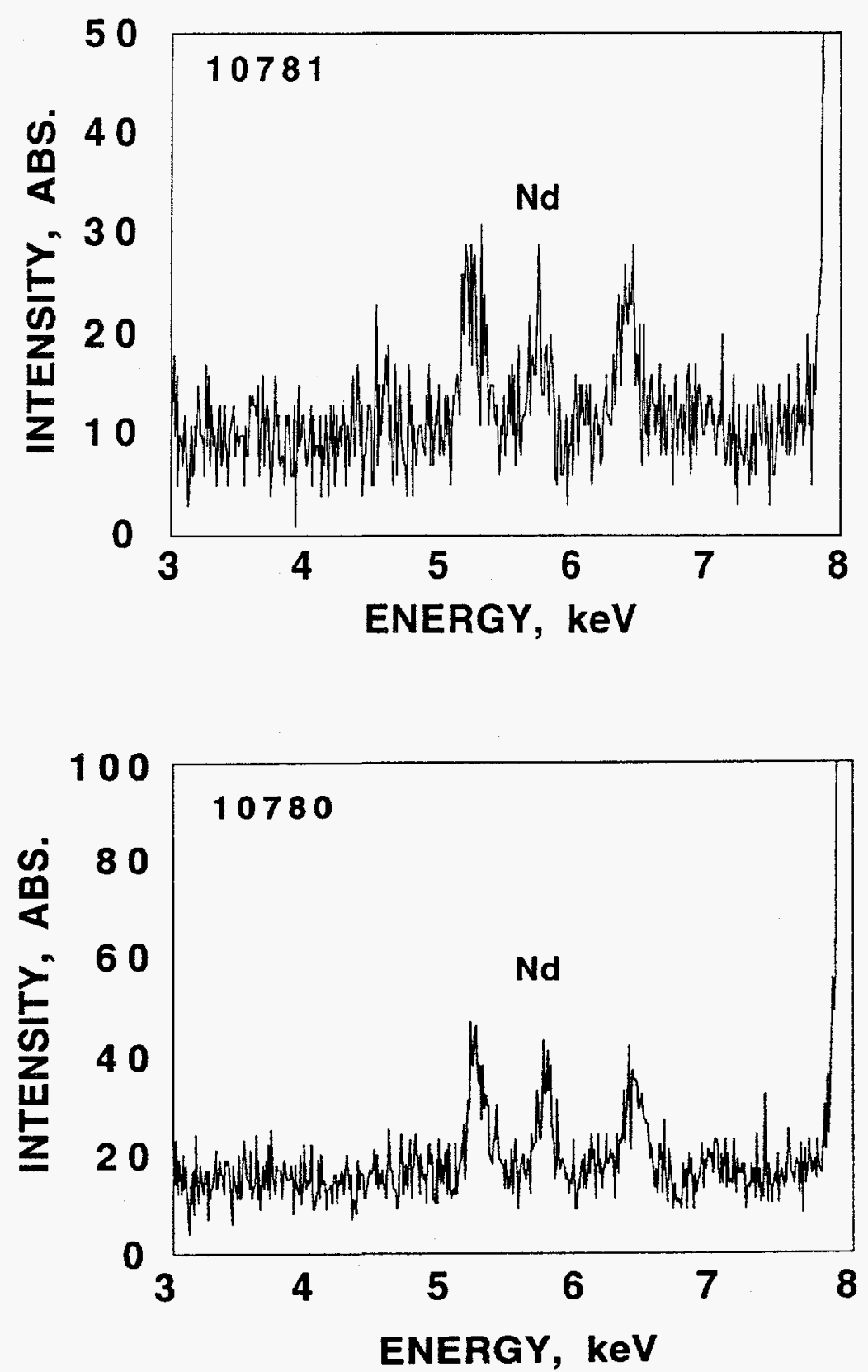

Fig. IV-9. EDS Spectra from Neodymium-Complexed Charcoal Particle. Spectrum 10780 is from the interior and Spectrum 10781 was acquired from approximately the outer $25 \mathrm{~nm}$ of the polymer surface (see Fig. IV-8). L series lines of neodymium are present in both spectra. 


\section{SIMULANT WASTE STREAM TESTING ON MACS PARTICLES}

\section{A. PFP Simulant Waste Stream Solution}

\section{Preparation}

Table V-1 shows the ion concentrations of major components of the PFP simulant waste, used for $\mathrm{K}_{\mathrm{d}}$ determinations. The solution was spiked with either ${ }^{238} \mathrm{Pu}$ or ${ }^{241} \mathrm{Am}$.

\section{2. $\quad$ Results and Discussion}

The $K_{d}$ values for plutonium(IV) in the PFP simulant were $\sim 20,000$. However, americium showed $K_{d}$ values $\sim 100$. Figure $V-1$ shows the extraction results for particles saturated with various concentrations of CMPO/TBP. The $\mathrm{K}_{\mathrm{d}}$ values showed little dependence on CMPO concentration for either americium or plutonium (Fig. V-1). Plutonium(IV) is strongly complexed by fluoride, which limits its extractability with CMPO; however, results from this study showed that plutonium is highly extractable even in the presence of fluoride. The low $K_{d}$ for americium is probably not due to fluoride competition for the actinide. The high iron concentration in the simulant solution may interfere with americium extraction because the iron complexes with CMPO.

Table V-1. PFP Simulant Waste Composition

\begin{tabular}{cc}
\hline $\begin{array}{c}\text { Ionic } \\
\text { Component }\end{array}$ & $\begin{array}{c}\text { Concentration, } \\
\text { M }\end{array}$ \\
\hline & $1.50 \mathrm{E}+00$ \\
$\mathrm{H}^{+}$ & $7.00 \mathrm{E}-05$ \\
$\mathrm{Be}^{2+}$ & $4.00 \mathrm{E}-02$ \\
$\mathrm{Na}^{+}$ & $6.00 \mathrm{E}-02$ \\
$\mathrm{Mg}^{2+}$ & $4.30 \mathrm{E}-01$ \\
$\mathrm{Al}^{3+}$ & $3.00 \mathrm{E}-03$ \\
$\mathrm{~K}^{+}$ & $6.00 \mathrm{E}-02$ \\
$\mathrm{Ca}^{2+}$ & $4.00 \mathrm{E}-04$ \\
$\mathrm{Cr}^{3+}$ & $3.00 \mathrm{E}-03$ \\
$\mathrm{Mn}^{2+}$ & $3.00 \mathrm{E}-02$ \\
$\mathrm{Fe}^{3+}$ & $8.00 \mathrm{E}-02$ \\
$\mathrm{Ni}^{2+}$ & $3.00 \mathrm{E}-04$ \\
$\mathrm{Cu}^{2+}$ & $6.00 \mathrm{E}-04$ \\
$\mathrm{Zn}^{2+}$ & $5.00 \mathrm{E}-04$ \\
$\mathrm{~Pb}^{2+}$ & $9.00 \mathrm{E}-02$ \\
$\mathrm{~F}^{-}$ & $1.00 \mathrm{E}-02$ \\
$\mathrm{SO}_{4}^{2-}$ & $3.05 \mathrm{E}+00$ \\
$\mathrm{NO}_{3}{ }^{2}$ &
\end{tabular}




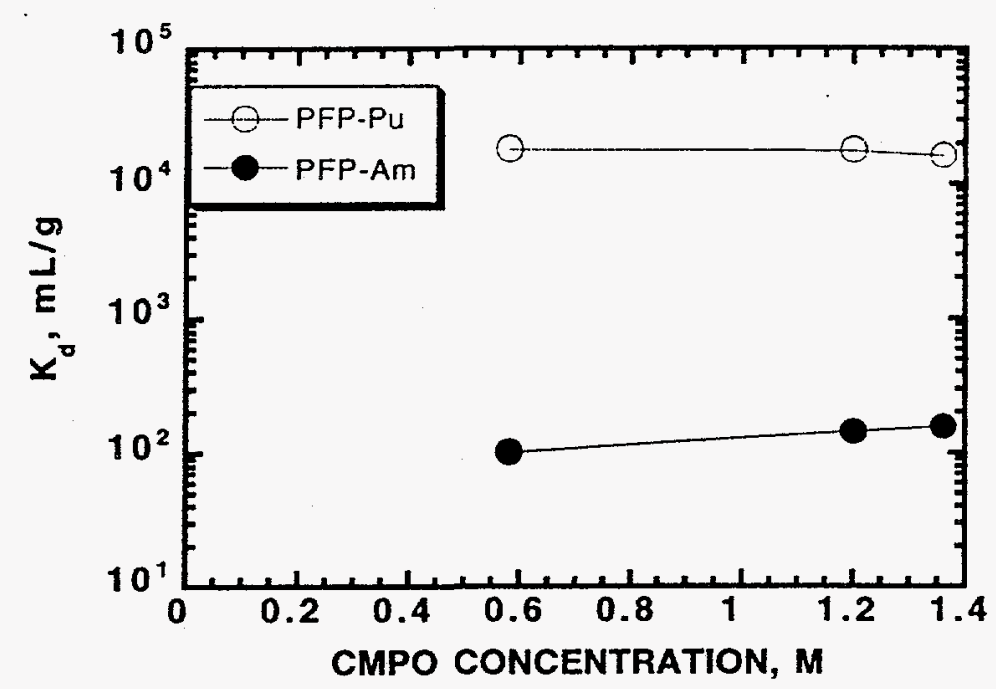

Fig. V-1. Americium and Plutonium Separation from PFP Simulant Solution at $25^{\circ} \mathrm{C}$ by CMPO/TBP-Coated Particles

To limit iron extraction, oxalic acid was added to the PFP simulant at a concentration based on speciation calculations from the Generix TRUEX Model (GTM). The concentration of free iron was calculated to be $0.001 \underline{\mathrm{M}}$ for a $0.28 \underline{\mathrm{M}}$ oxalic acid solution. The addition of oxalic acid resulted in an increase of the $K_{d}$ for americium from 100 to 3500 for $1.5 \mathrm{M}$ CMPO particles at room temperature.

\section{B. Cesium Supernatant Simulant Waste Stream}

\section{Preparation}

Table V-2 shows the concentrations and components of cesium supernatant waste simulant solution, used for $K_{\mathbf{d}}$ determinations.

\section{2. $\quad$ Results and Discussion}

The $K_{d}$ values for americium in this highly basic simulant ranged from 8,000 to 30,000 (Fig. V-2). Results showed considerable scatter, due to americium adsorption on the glass and colloid formation. Blank measurements on a glass test tube showed americium adsorption by the glass to be $\sim 6 \%$ of the total activity. The coated particles caused a significant reduction (99\%) in the activity of the solution. Although the inhomogeneity of the sample produced large uncertainties, the $K_{d}$ values are clearly high in basic solution, probably due to an activation of magnetite particles that aids in TRU adsorption. This has been observed in magnetite precipitation tests at the Rocky Flats plant [KOCHEN, BOYD] where the TRU elements showed decontamination factor (DF) values of $10^{4}$ to $10^{6}$ at high $\mathrm{pH}$. The activation of magnetite is driven by two factors: (1) the small particles $(<10 \mu \mathrm{m})$ have a larger surface area for TRU adsorption, and (2) magnetite adsorbs hydroxide ions, and metal ions bond to the magnetite surface through these hydroxide ions. There was little change in $K_{d}$ as a function of CMPO concentration (Fig. V-2). Since the waste stream was alkaline, the americium species is uncertain and it was probably in a colloidal state. This may have contributed 
Table V-2. Hanford Tank Cesium Supernatant Simulant Composition

\begin{tabular}{cc}
\hline \multicolumn{2}{c}{ Cs Tank Simulant } \\
\hline $\begin{array}{c}\text { Ionic } \\
\text { Component }\end{array}$ & $\begin{array}{c}\text { Concentration, } \\
\mathrm{M}\end{array}$ \\
\hline & \\
$\mathrm{Na}^{+}$ & $8.83 \mathrm{E}+00$ \\
$\mathrm{~K}^{+}$ & $9.35 \mathrm{E}-02$ \\
$\mathrm{Cs}^{+}$ & $5.31 \mathrm{E}-05$ \\
$\mathrm{OH}^{-}$ & $6.55 \mathrm{E}+00$ \\
$\mathrm{NO}_{3}^{-}$ & $1.09 \mathrm{E}+00$ \\
$\mathrm{NO}_{2}^{-}$ & $8.09 \mathrm{E}-00$ \\
$\mathrm{Al}^{-}\left(\mathrm{OH}_{4}\right)_{4}^{-}$ & $2.06 \mathrm{E}-02$ \\
$\mathrm{CO}_{3}^{2-}$ & $2.22 \mathrm{E}-01$ \\
$\mathrm{CrO}_{4}^{2-}$ & $4.37 \mathrm{E}-03$ \\
$\mathrm{PO}_{4}{ }^{3-}$ & $8.00 \mathrm{E}-04$ \\
\hline
\end{tabular}

aSpiked with either ${ }^{238} \mathrm{Pu}$ or ${ }^{241} \mathrm{Am}$

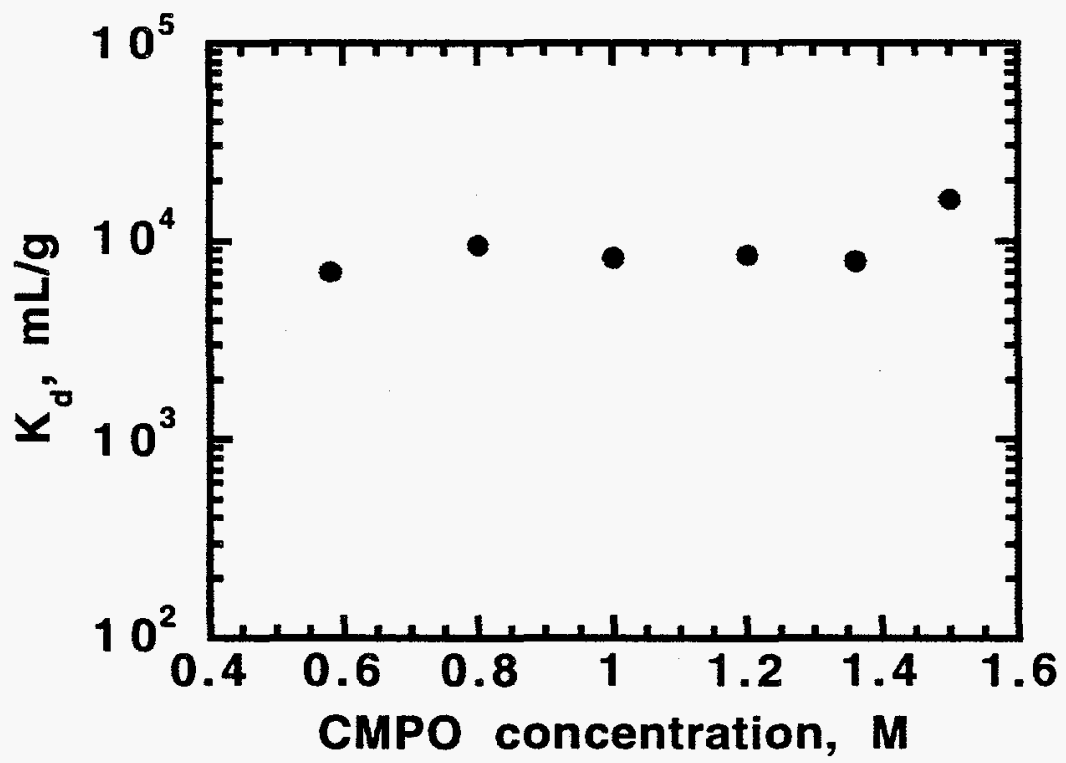

Fig. V-2. Americium Separation from Hanford Tank Supernatant Simulant at $25^{\circ} \mathrm{C}$ by MACS Particles Loaded with CMPO/TBP. Values are means of several determinations. 
to the large variation between duplicate runs. Nevertheless, americium was efficiently separated from the cesium simulant solution, which itself contributes to the separation because of its high nitrate activity and lack of interfering chemical species.

\section{Stripping Measurements}

\section{1. $\quad$ Objective}

Because of the high levels of TRU extraction obtained by using magnetic particles, indicated by the large $K_{d}$ values, an efficient recovery stage is required to regenerate the particles, and the usual stripping processes in the treatment of nitrate waste streams (using dilute nitric acid for americium and an aqueous phase complexant or reducing agent for plutonium) would be inefficient. (The large $K_{d}$ values in the MACS process are partly due to the high concentration of CMPO.) A three-step stripping process is necessary. In the first step, the complexants (CMPO/TBP) and the extracted TRU elements are stripped from the particles by using a hydrocarbon or an alcohol. In the second step, the TRU elements are stripped from the organic phase, which is now a dilute CMPO solution, by using an appropriate aqueous phase. Finally, the volatile hydrocarbon or alcohol (e.g., octanol) is evaporated leaving the residual CMPO/TBP on the particle surface.

\section{2. $\quad$ Stripping Experiments}

The radionuclide-loaded magnetic particles from a PFP simulant extraction were dried in preparation for stripping experiments to test step one of the three-step process. An alcohol was added to the particles as stripping agent and contacted following a procedure similar to that used in the extraction experiments (Sect. IV). The volume of stripping agent was one-hundred times smaller than the aqueous phase volume used for extraction experiments. Measurements of stripping $\mathrm{K}_{\mathrm{d}}$ were similar to those of extraction $\mathrm{K}_{\mathrm{d}}$ (Sect. IV-D).

\section{3. $\quad$ Results and Discussion}

Table V-3 gives the stripping $K_{d}$ values for plutonium. Some negative values, not reported, were attributed to errors in the mass balance assumptions (e.g., carry-over of phases, conservation of particle mass) [APPENDIX E]. The $\mathrm{K}_{\mathrm{d}}$ values were derived from Eqs. V-1 and V-2.

Equation V-1 is the mass balance equation:

$$
\left.\mathrm{g}_{\mathrm{p}}[\mathrm{cpm} / \mathrm{g}]^{\text {original }}=\mathrm{g}_{\mathrm{p}}[\mathrm{cpm} / \mathrm{g}]\right]^{\text {final }}+(\mathrm{mL})[\mathrm{cpm} / \mathrm{mL}]^{\text {final }}
$$

assuming that there is negligible loss in particle mass before and after stripping.

Table V-3. Stripping $\mathrm{K}_{\mathrm{d}}$ for ${ }^{238} \mathrm{Pu}$ in PFP Simulant

\begin{tabular}{ccccc}
\hline Sample & $\begin{array}{c}\text { Stripping } \\
\text { Solvent }\end{array}$ & $\begin{array}{c}\text { Loading } \mathrm{K}_{\mathrm{d}}, \\
\mathrm{mL} / \mathrm{g}\end{array}$ & $\begin{array}{c}\text { Stripping } \mathrm{K}_{\mathrm{d}}, \\
\mathrm{mL} / \mathrm{g}\end{array}$ & $\begin{array}{c}\text { Volume } \\
\text { Reduction, } \\
\text { Abs. }\end{array}$ \\
\hline $1.2 \underline{\mathrm{M}}$ CMPO & ethanol & 1850 & 0.73 & 400 \\
$1.0 \mathrm{M}$ CMPO & butyl alcohol & 3323 & 4.75 & 100 \\
$1.0 \underline{\mathrm{M}}$ CMPO & ethanol & 1553 & 0.65 & 100 \\
\hline
\end{tabular}




$$
K_{d}^{\text {strip }}=\frac{\left[\left(\frac{g_{p}}{V}\right) K_{d}^{\text {ext }} C_{\text {final }}^{\text {ext }}-C_{\text {final }}^{\text {strip }}\right]}{\left(\frac{g_{p}}{V}\right) C_{\text {final }}^{\text {strip }}}
$$

where

$$
\begin{aligned}
g_{p} & =\text { mass of the particles, } g \\
V & =\text { volume of waste solution, } m L \\
C_{\text {final }}^{\text {strip }} & =\text { final concentration after stripping } \\
C_{\text {final }}^{\text {ext }} & =\text { final concentration after extraction } \\
\mathrm{K}_{\mathrm{d}}^{\text {ext }} & =\text { extraction partition coefficient }
\end{aligned}
$$

The results are promising, but work is needed to develop a stripping step that can produce a stripping stage $K_{d}$ value of $1 / 1000$ for an efficient recovery process.

With the stripping protocol we were easily able to reduce the volume by a factor of 400 from the original feed solution. Since the volume of solvent on the particles is small, with O/A ratios $\leq 0.01$, even higher volume reductions should be attainable. For a one-batch operation, the stripping stage recovered $>99 \%$ of the plutonium and up to $92 \%$ of the americium, i.e., an overall TRU recovery $>95 \%$. 
VI. MATERIAL STABILITY

\section{A. Chemical Stability of Particles - Dissolution in Nitric Acid}

\section{Objective}

Magnetite is soluble in nitric acid, but the polymeric coating can partially protect it. Dissolution of the magnetite would inhibit particle recovery and hinder application of the MACS process. A series of experiments was performed to determine the extent of dissolution of magnetite from the particles as a function of nitric acid concentration.

\section{Experimental}

Six samples of MACS charcoal particles loaded with CMPO/TBP $(0.18 \mathrm{~mL} / \mathrm{g})$ were weighed and each mixed with $5 \mathrm{~mL}$ of a nitric acid solution. These samples were mixed following the extraction procedure and allowed to settle for 336 hours (2 weeks). Magnetic separation was performed and aliquots ( $1 \mathrm{~mL}$ ) were analyzed for iron using inductively coupled plasma (ICP) analysis. An aqueous-phase sample without any particles present was analyzed as the background.

\section{Results and Discussion}

Iron from the magnetite dissolved in nitric acid and the dissolution increased with increasing acid concentration, as evidenced by ICP analysis. The dissolution occurred linearly (Fig. VI-1) throughout the nitric acid range used, which included the expected MACS process range of $2-4 \mathrm{M} \mathrm{HNO}_{3}$. The dissolution is due to the presence of exposed magnetite, evident in the TEM micrographs (Fig. VI-2). A significant portion of the magnetite in the irregularly-shaped particles was in the outer sphere of the polymeric material. The information provided by these experiments is limited to dissolved iron, not the magnetite remaining on the particles. In the shorter contact time in MACS processing (minutes), the effect is expected to be smaller, but this chemical degradation remains a major concern for process recycling.

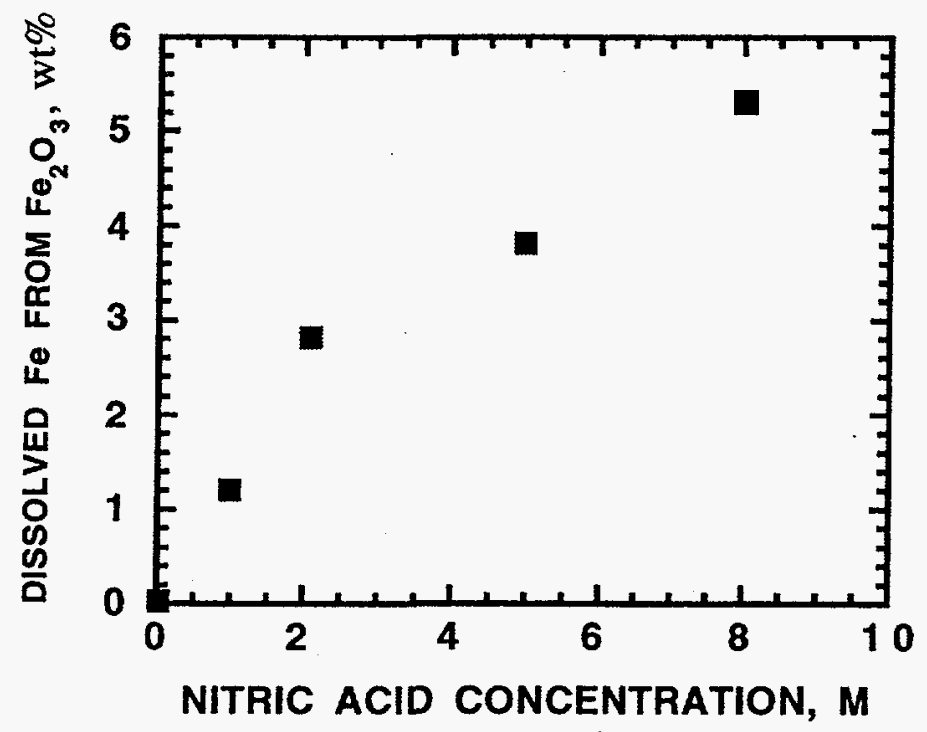

Fig. VI-1. Dissolution of Iron from Magnetite vs. Nitric Acid Concentration 
The TEM study of the charcoal particles illustrated various features of the magnetite location and size distribution. A TEM micrograph (Fig. VI-2) shows the large surface areas (irregular shape) of these magnetic particles. The dark areas represent crystalline magnetite particles and the adjacent lighter areas contain the charcoal coating. The fraction of magnetite to polymer varies substantially and the location of magnetite on the outer surface of the polymer is apparent. The micrograph also illustrates that the magnetite/polymer interface is thin or weak. These thin, exposed, or weak-link sites, which depend on the particle manufacturing procedure, could act as active sites for dissolution of the magnetite.

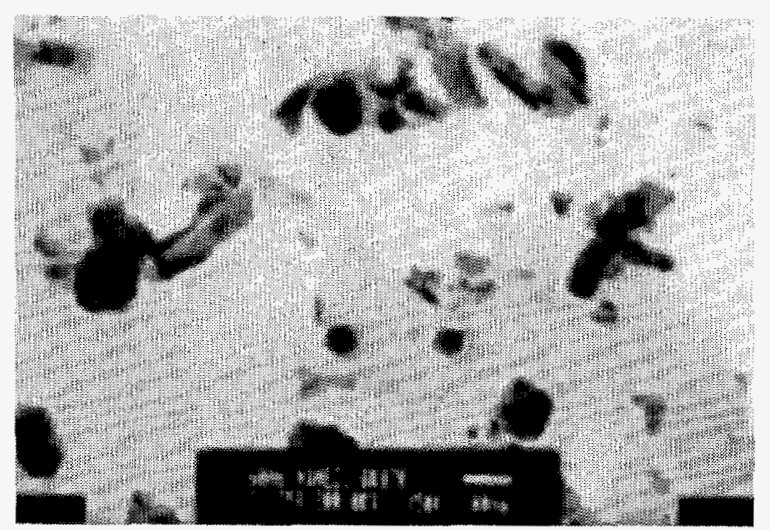

Fig. VI-2. TEM Micrograph of Magnetic Particles with Polymeric Coating 


\section{CONCLUSIONS}

The MACS process shows promise as an efficient and compact separation technology. The large $\mathrm{K}_{\mathbf{d}}$ values for plutonium and americium measured for MACS particles, compared with those calculated from traditional liquid/liquid extraction experiments for similar waste streams, illustrate the higher efficiency of separation using the MACS process. Extensive study of the coating process has led to production of better and more homogeneous coated particles by a simple chemical adsorption technique. Although it is possible to bind the extractant onto the particles chemically, we have concentrated on chemical adsorption. The studies of plutonium and americium extraction as a function of nitric acid concentration suggested that the CMPO/TBP extraction species are different from those modeled for the TRUEX process by the GTM. Further studies are required to model the data and determine a precise extraction mechanism. Stripping the particles by using alcohols instead of stripping agent and hydrocarbons has been successful in providing large volume reduction. The stripping process is a three-stage process and activities still need to be optimized.

Magnetite dissolution in acid could be a limitation of the recyclable batch process. The possibility of designing particles with minimal exposed magnetite should be investigated in collaboration with manufacturers. On the other hand, in MACS applications for basic solutions containing TRU, exposure of the magnetite could lead to an increased sorption. 


\section{APPENDIX A}

\section{NATURE OF THE SUPERPARAMAGNETIC PARTICLE AND SELECTION FOR MACS APPLICATIONS}

\section{Superparamagnetic Particles Applications}

Superparamagnetic particles have an extensive variety of applications in the biotechnological field, and serve as detection and monitoring agents and in development of analytical techniques. These particles are used in immunological analysis, chemiluminescense [STABLER], and immunomagnetic separation of food bacteria [SKJERVE], and genes [LUND]. Magnetic particles are available from several commercial suppliers, in a variety of sizes. Paricles vary in magnetic properties and in their functionalized and nonfunctionalized polymeric coatings. On the basis of our own experience, the literature, and discussions with the suppliers' technical experts, we have chosen the materials best suited for our application, that is, separation of TRU elements from wastes.

\section{Chemical Coatings}

To achieve a higher chemical affinity between CMPO/TBP and the magnetic particles, a variety of polymers were tested for use as coating material. Phosphine and phosphate-based polymers are not commercially available because of problems that have been observed in the biotechnical applications of these functional groups due to bacterial growth. A slightly porous polymer with different chemical affinity than phosphine oxides allows for greater acceptance of CMPO/TBP. So far, five such polymers have been tested. Their structures are shown in Figs. A-1 through A-5 [KIRK-OTHMER-A]:

\section{Cellulose}

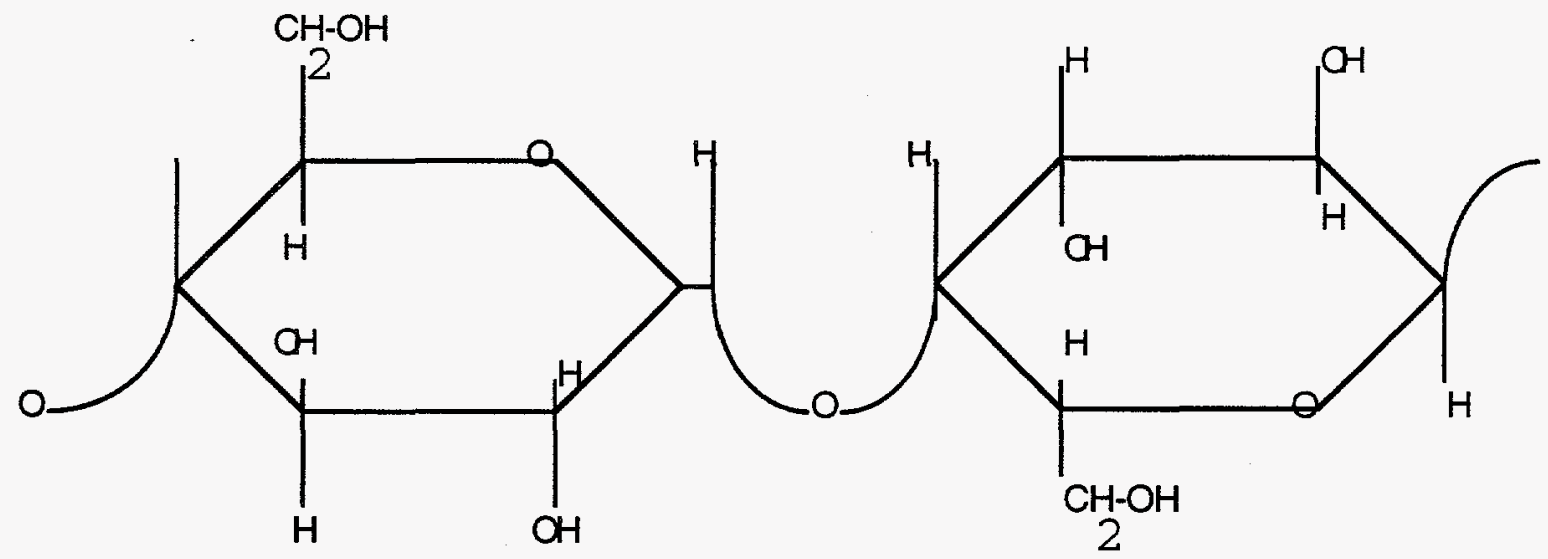

Fig. A-1. Structure of Cellulose 
Divinylbenzene

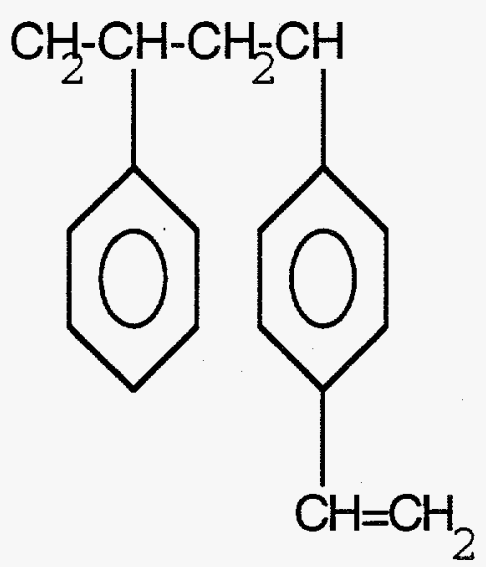

Fig. A-2. Structure of Divinylbenzene

Polyacrolein

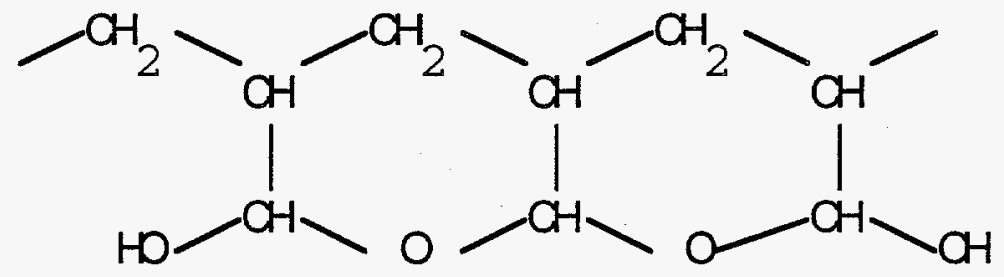

Fig. A-3. Structure of Polyacrolein

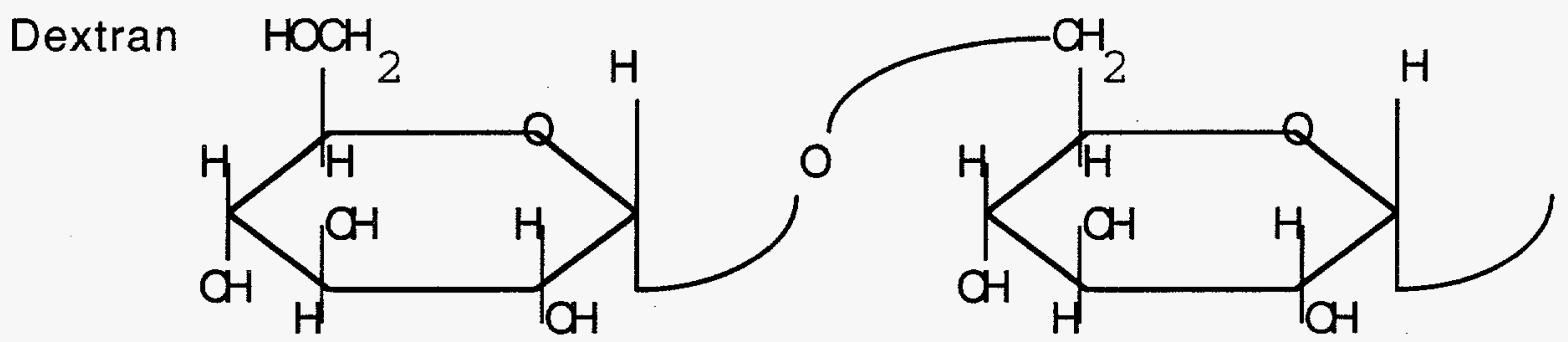

Fig. A-4. Structure of Dextran 
$\mathrm{N}, \mathrm{N}^{\prime}$-Methylenebisacrylamide

\section{$\left(\mathrm{CH}_{2}=\mathrm{CHCONH}\right)_{2} \mathrm{CH}_{2}$}

Fig. A-5. Structure of N,N'-Methylenebisacrylamide

We are currently testing five new polymers (discussed below). We selected these polymers on the basis of similarities (in structure, chemical affinity with CMPO/TBP, solubility, and melting point) to previously tested polymers that produced desirable results [KIRK-OTHMER-A, KIRKOTHMER-B, KIRK-OTHMER-C, EPST].

\section{Possibility of Chemical Modification of Particles Surface}

The availability of particles with specific functional groups on the polymeric coating provides the ability to chemically synthesize CMPO and TBP onto the particles. We are exploring this possibility in the literature [PAINE], but due to the level of the program funding, only efforts related to sorption of the particles are being pursued at the moment.

\section{Polymer Coatings}

Listed below are some of the polymers that can be prepared on superparamagnetic particles and may have chemical and physical affinity toward the CMPO and TBP extractants.

Polylbis(methylamino)phosphazenel is an experimental carrier polymer for chemotherapeutic agents (Fig. A-6). It has a $\mathbf{T}_{\mathbf{g}}$ (the temperature of the polymer's structural transition to a glass state) of $14^{\circ} \mathrm{C}$, but is soluble in water.

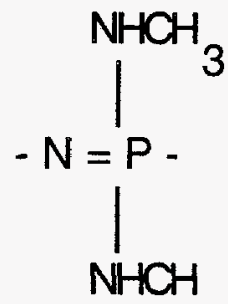

Fig. A-6. Poly[bis(methylamino)phosphazene] 
Poly(methylacrylate) is used in surface coatings (Fig. A-7). It is soluble in water and alcohol, but not in hexane [ALLCOCK].<smiles>CCC(=O)OC</smiles>

Fig. A-7. Poly(methylacrylate)

N-t-Butylacrylamide has a structure similar to $\mathrm{N}, \mathrm{N}^{\prime}$-Methylenebisacrylamide, which has proved successful based on $\mathrm{K}_{\mathrm{d}}$ results (Fig. A-8). This polymer has a melting point between $128-130^{\circ} \mathrm{C}$. It is slightly more soluble than $\mathrm{N}, \mathrm{N}^{\prime}$-Methylenebisacrylamide in volatile organic substances.

\section{$-\mathrm{CH}_{2}=\mathrm{CHCONHC}\left(\mathrm{CH}_{3}\right)_{3}-$}

Fig. A-8. N-t-Butylacrylamide

Methacrylamide also has a structure that is similar to N,N'-Methylenebisacrylamide (Fig. A-9). Its melting point is $110^{\circ} \mathrm{C}$, but is soluble in water, alcohols and heptane.

\section{$-\mathrm{CH}_{2}=\mathrm{C}\left(\mathrm{CH}_{3}\right) \mathrm{CONH}_{2}-$}

Fig. A-9. Methacrylamide

Variations of the Polyacrolein structure which have similar carbon chains can be achieved by redox polymerization (see Fig. A-10).
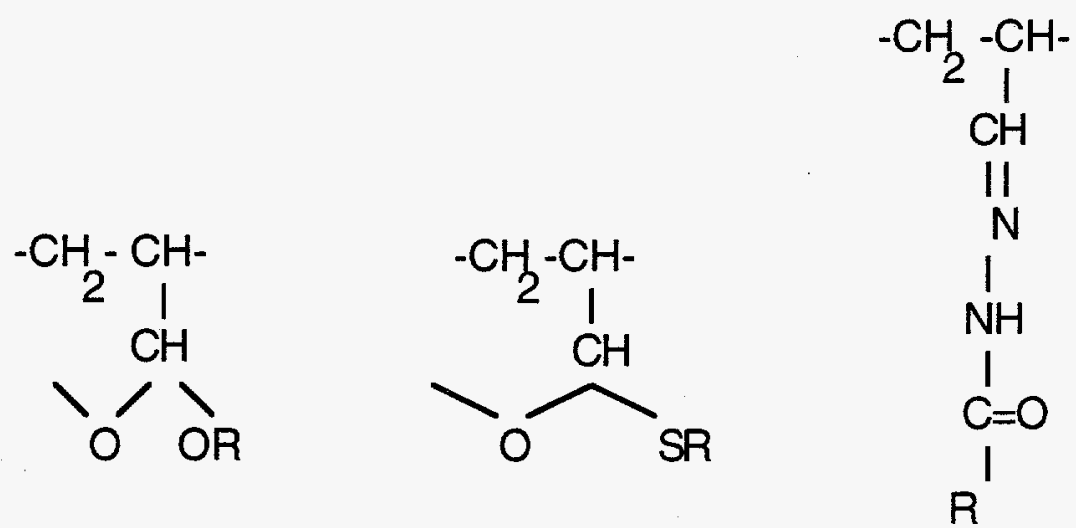

Fig. A-10. Variations of the Polyacrolein Structure 
So far two chemical companies have been contacted to explore the possibilities of purchasing beads precoated with these polymers.

Bangs Laboratories, Inc. - This company will not custom coat the beads, but did provide names of laboratories that specialize in coating beads (see Table A-1). Cortex Biochem - This company analyzed the polymers requested and sent a proposed minimum order and cost estimate (see Table A-2).

Table A-1. Microparticle Coating Contractors and Consultants

\begin{tabular}{|c|c|c|}
\hline Name & Address & Tel. and Fax Numbers \\
\hline Gerald Vosika, Ph.D. & $\begin{array}{l}\text { Immunotherapeutics, Inc. } \\
1919 \text { N. Elm St. } \\
\text { Fargo, ND } 58102\end{array}$ & $\begin{array}{l}\text { Tel: } 701-232-9575 \\
\text { FAX: } 701-237-9275\end{array}$ \\
\hline Frank Falkowski & $\begin{array}{l}\text { Kara Biologicals } \\
\text { P.O. Box } 62 \\
\text { Stanton, NJ } 08885\end{array}$ & $\begin{array}{l}\text { Tel: } 908-236-2455 \\
\text { FAX: } 908-236-7273\end{array}$ \\
\hline Hans Hager, Ph.D. & $\begin{array}{l}\text { Consultant } \\
\text { Cuddledyke House } \\
\text { The Pingle, Upwell } \\
\text { Wisbech } \\
\text { Cambridge PE149DN } \\
\text { United Kingdom } \\
\text { (Consultant for research and } \\
\text { development Immuno-Diagnostics) }\end{array}$ & $\begin{array}{l}\text { Tel: } 01171353667034 \\
\text { Ely, Cambridge } \\
\text { 011 } 81945772393 \\
\text { FAX: } 01181945772140\end{array}$ \\
\hline Jeanne Dunham & $\begin{array}{l}\text { Bioserv } \\
11211 \text { Sorrento Valley Rd. } \\
\text { Suite Q } \\
\text { San Diego, CA } 92121 \\
\text { (No research facilities, manufacturing } \\
\text { only) }\end{array}$ & $\begin{array}{l}\text { Tel: } 619-450-3123 \\
\text { FAX: } 619-450-0785\end{array}$ \\
\hline Jemo Kang, Ph.D. & $\begin{array}{l}\text { Princeton BioMedica Corp. } \\
4242 \text { US Rt. } 1 \\
\text { Monmouth, NJ } 08852\end{array}$ & $\begin{array}{l}\text { Tel: } 908-274-1000 \\
\text { FAX: } 908-274-1010\end{array}$ \\
\hline Wayne Henry & $\begin{array}{l}\text { AlerChek, Inc. } \\
203 \text { Anderson Street } \\
\text { Portland, ME } 04101 \\
\text { (Carboxyl, Aldehyde or amine covalent } \\
\text { coupling of proteins or peptides to all } \\
\text { types of hydrophobic surfaces) }\end{array}$ & $\begin{array}{l}\text { Tel: } 207-775-2574 \\
\text { FAX: } 207-775-0594\end{array}$ \\
\hline Tony Bebbington & $\begin{array}{l}\text { Bebbington Bioclinical, Inc. } \\
20 \text { Wright Ave., Unit } 2 \\
\text { Dartmough } \\
\text { Nova Scotia, B2Y 5M9 } \\
\text { Canada }\end{array}$ & $\begin{array}{l}\text { Tel: } 902-448-8180 \\
\text { FAX: } 902-468-8559\end{array}$ \\
\hline Michael A. Huchital, Ph.D. & $\begin{array}{l}\text { Quality Antisera } \\
\text { Development \& Production } \\
27 \text { Magnolia Lane } \\
\text { Warwick, NY 01990 }\end{array}$ & $\begin{array}{l}\text { Tel: 914-986-5268 } \\
\text { Tel: } 914-888-2766\end{array}$ \\
\hline
\end{tabular}


Table A-1. (contd)

\begin{tabular}{|c|c|c|}
\hline Name & Address & Tel. and Fax Numbers \\
\hline Bruce Clinton, Ph.D. & $\begin{array}{l}\text { Trinity Laboratories, Inc. } \\
7517 \text { Precision Drive } \\
\text { Suite } 107 \\
\text { Raleigh, NC } 27613\end{array}$ & $\begin{array}{l}\text { Tel: } 919-598-5000 \\
\text { FAX: } 919-598-5003\end{array}$ \\
\hline Duncan S. Pepper, Ph.D & $\begin{array}{l}\text { HQ Laboratories } \\
2 \text { Forrest Road } \\
\text { Edinburgh EH1 2QN } \\
\text { Scotland }\end{array}$ & $\begin{array}{l}\text { Tel: } 031-225-2875 \\
\text { FAX: } 031-220-1893\end{array}$ \\
\hline Jeffrey Palce & $\begin{array}{l}\text { TherImmune Scientific, Ltd. } \\
\text { c/o Ryerson Polytechnical } \\
350 \text { Victoria St. } \\
\text { Toronto, Ontario M5B } 2 \mathrm{~K} 3 \\
\text { Canada } \\
\text { (Specializing in surface activator work, } \\
\text { especially hydrazide activated 96-well } \\
\text { plates) }\end{array}$ & $\begin{array}{l}\text { Tel: } 416-979-5295 \\
\text { FAX: } 416-979-5294\end{array}$ \\
\hline $\begin{array}{l}\text { David Newman, Ph.D } \\
\text { Christopher Price, Ph.D. }\end{array}$ & $\begin{array}{l}\text { London Hospital Med. School } \\
\text { Dept. of Clinical Bio-Chemistry } \\
\text { Univ. of London/Turner St. } \\
\text { London E12AD } \\
\text { United Kingdom }\end{array}$ & $\begin{array}{l}\text { Tel: } 011-44-71-377-7241 \\
\text { FAX: } 011-44-71-377-1544\end{array}$ \\
\hline
\end{tabular}


I. Polylbis(methylamino)phosphazinel

We were not able to identify any references concerning the monomer from which we would produce the polymer for this material. If you can locate a producer of the monomer, please advise us on that issue. I will reply on this project under separate cover.

II. Poly(methylacrylate)

Minimum quantity manufactured and supplied.

III. N-t-Butylacrylate

We do not have specific experience working with this polymer. We do however belive that from an empirical understanding of similar materials, and with a bit of $R / D$ we could synthesize this material quickly.

Minimum quantity manufactured and supplied

DELIVERY FROM ORDER PLACEMENT

IV. N, N'-Methylenebisacrylamide

Minimum quantity manufactured and supplied

DELIVERY FROM ORDER PLACEMENT

\section{Divinylbenzene/Polystyrene}

Minimum quantity manufactured and supplied DELIVERY FROM ORDER PLACEMENT

\section{Phosphine as functional group}

Phosphine chemicals are exceptionally toxic (related to nerve gas) and hazardous and require very specialized equipment and facilities to meet the handling and safety requirements. At the current time and with our present equipment we are unable to assist you unless we are able to upgrade and certify our facility for this project. 


\section{APPENDIX B \\ ERROR CALCULATION IN PARTITION COEFFICIENT}

Difficulties can arise in analyzing $K_{d}$ data for trends and comparisons to related systems because of the lack of an error estimate. This section presents a method for calculating the error in the $\mathrm{K}_{\mathrm{d}}$ value based on conventional radiation counting statistics. The requirement for this type of treatment is that all parameters or events are independent of one another. In other words, the outcome of one event has no influence on that of another. For our purposes, the events are the aliquot count rates, contact volume, and the mass of the particles used for extraction. In general, the error calculation follows in the form of Eq. B-1 [TSOULFANIDIS].

$$
(\Delta \mathrm{f})^{2}=\left(\frac{\partial \mathrm{f}}{\partial \mathrm{x}_{1}}\right)^{2}\left(\Delta \mathrm{x}_{1}\right)^{2}+\left(\frac{\partial \mathrm{f}}{\partial \mathrm{x}_{2}}\right)^{2}\left(\Delta \mathrm{x}_{2}\right)^{2}+\left(\frac{\partial \mathrm{f}}{\partial \mathrm{x}_{3}}\right)^{2}\left(\Delta \mathrm{x}_{3}\right)^{2}+\ldots
$$

where

$$
f=f\left(x_{1}, x_{2}, x_{3}, \ldots\right)
$$

The function we are concerned with is Eq. B-2

$$
K_{d}=\left(\frac{C_{i}-C_{f}}{C_{f}}\right) \times \frac{v}{m}
$$

where

$$
\begin{aligned}
& \mathrm{V}=\text { contact volume of americium solution, } \mathrm{mL} \\
& \mathbf{m}=\text { mass of particles, } \mathrm{g} \\
& \mathrm{C}_{\mathbf{i}}=\text { initial stock solution counts before contact } \\
& \mathrm{C}_{\mathbf{f}}=\text { final solution counts after contact }
\end{aligned}
$$

It would be preferable to use the method of partial derivatives (Eq. B-1) to calculate an uncertainty in the measured/calculated $K_{d}$.

$A K_{d}$ equation was created which incorporated all possible sources of error and the partial derivative error equation was applied to it. To determine measurement errors, manufacturers' estimates were always used. The following is the mass balance which was used to determine the $\mathrm{K}_{\mathrm{d}}$ (Eq. B-3).

$$
\left[\left(\mathrm{mL}_{\mathrm{s}}\right)(\mathrm{CPM} / \mathrm{mL})\right]_{\text {initial }}=\left[\left(\mathrm{g}_{\mathrm{p}}\right)(\mathrm{CPM} / \mathrm{g})\right]_{\text {final }}+\left[\left(\mathrm{mL}_{\mathrm{s}}\right)(\mathrm{CPM} / \mathrm{mL})\right]_{\text {final }}
$$

where

$$
\begin{aligned}
& \mathrm{CPM} / \mathrm{mL}=\text { the counts per minute per unit volume of a sample, } \\
& \mathrm{CPM} / \mathrm{g}=\text { the counts per minute per unit weight of particles, } \\
& \mathrm{g}_{\mathrm{p}} \quad=\text { the mass of the particles } \\
& \mathrm{mL}_{\mathrm{S}} \quad=\text { the volume of a sample }
\end{aligned}
$$

Rearranging the terms and substituting in the $\mathrm{K}_{\mathbf{d}}$ term, Eq. B-4 arises. 


$$
\mathrm{K}_{\mathrm{d}}\left[\left(\mathrm{g}_{\mathrm{p}}\right)(\mathrm{CPM} / \mathrm{mL})\right]_{\text {final }}=\left[\left(\mathrm{mL}_{\mathrm{s}}\right)(\mathrm{CPM} / \mathrm{mL})\right]_{\text {initial }}-\left[\left(\mathrm{mL}_{\mathrm{s}}\right)(\mathrm{CPM} / \mathrm{mL})\right]_{\text {final }}
$$

And solving for $\mathrm{K}_{\mathrm{d}}$ (Eq. B-5), we have,

$$
\mathrm{K}_{\mathrm{d}}=\frac{\left[\left(\mathrm{mL}_{\mathrm{s}}\right)(\mathrm{CPM} / \mathrm{mL})\right]_{\text {initial }}-\left[\left(\mathrm{mL}_{\mathrm{s}}\right)(\mathrm{CPM} / \mathrm{mL})\right]_{\text {final }}}{\left[\left(\mathrm{g}_{\mathrm{p}}\right)(\mathrm{CPM} / \mathrm{mL})\right]_{\text {final }}}
$$

The standard error equation (Eq. B-6),

$$
(\Delta f)^{2}=\left(\frac{\partial f}{\partial x_{1}}\right)^{2}\left(\Delta x_{1}\right)^{2}+\left(\frac{\partial f}{\partial x_{2}}\right)^{2}\left(\Delta x_{2}\right)^{2}+\left(\frac{\partial f}{\partial x_{3}}\right)^{2}\left(\Delta x_{3}\right)^{2}+\cdots
$$

becomes the following (Eq. B-7) when applied to the $K_{d}$ equation,

$$
\begin{aligned}
\left(\Delta \mathrm{K}_{\mathrm{d}}\right)^{2}= & \left(\frac{\partial \mathrm{K}_{\mathrm{d}}}{\partial \mathrm{mL}_{\mathrm{s}}}\right)^{2}\left(\Delta \mathrm{mL}_{\mathrm{s}}\right)^{2}+\left(\frac{\partial \mathrm{K}_{\mathrm{d}}}{\partial \mathrm{CPM}_{\text {init }}}\right)^{2}\left(\Delta \mathrm{CPM}_{\mathrm{init}}\right)^{2}+\left(\frac{\partial \mathrm{K}_{\mathrm{d}}}{\partial \mathrm{mL} \mathrm{L}_{\mathrm{init}}}\right)^{2}\left(\Delta \mathrm{mL}_{\mathrm{init}}\right)^{2}+ \\
& \left(\frac{\partial \mathrm{K}_{\mathrm{d}}}{\partial \mathrm{CPM}_{\text {fin }}}\right)^{2}\left(\Delta \mathrm{CPM}_{\mathrm{fin}}\right)^{2}+\left(\frac{\partial \mathrm{K}_{\mathrm{d}}}{\partial \mathrm{mL}_{\mathrm{fin}}}\right)^{2}\left(\Delta \mathrm{mL}_{\mathrm{fin}}\right)^{2}+\left(\frac{\partial \mathrm{K}_{\mathrm{d}}}{\partial \mathrm{g}_{\mathrm{p}}}\right)^{2}\left(\Delta \mathrm{g}_{\mathrm{p}}\right)^{2}
\end{aligned}
$$

where

$$
\begin{aligned}
& \left(\frac{\partial \mathrm{K}_{\mathrm{d}}}{\partial \mathrm{mL}}\right)^{2}\left(\Delta \mathrm{mL}_{\mathrm{s}}\right)^{2}=\left(\frac{\mathrm{CPM}_{\text {init }} \mathrm{mL}_{\mathrm{fin}}}{\mathrm{mL}_{\text {init }} \mathrm{CPM}_{\text {fing }}}-\frac{1}{\mathrm{~g}_{\mathrm{p}}}\right)^{2}\left(\Delta \mathrm{g}_{\mathrm{p}}\right)^{2}
\end{aligned}
$$

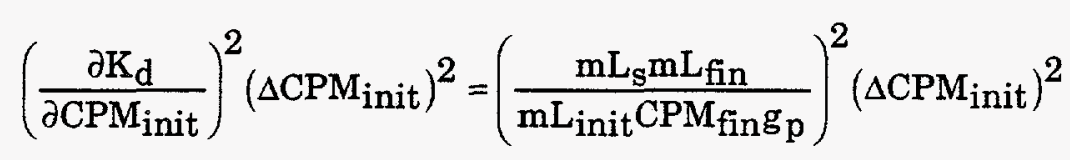

$$
\begin{aligned}
& \left(\frac{\partial \mathrm{K}_{\mathrm{d}}}{\partial \mathrm{mL}_{\text {init }}}\right)^{2}\left(\Delta \mathrm{mL} \mathrm{L}_{\mathrm{init}}\right)^{2}=\left(\frac{\mathrm{mL}_{\mathrm{s}} \mathrm{CPM}_{\text {init } \mathrm{mL}_{\mathrm{fin}}}}{\mathrm{mL}_{\text {init }}^{2} \mathrm{CPM}_{\text {fing }}}\right)^{2}\left(\Delta \mathrm{mL} \mathrm{L}_{\mathrm{init}}\right)^{2} \\
& \left(\frac{\partial \mathrm{K}_{\mathrm{d}}}{\partial \mathrm{CPM}_{\mathrm{fin}}}\right)^{2}\left(\Delta \mathrm{CPM}_{\mathrm{fin}}\right)^{2}=\left(\frac{\mathrm{mL}_{\mathrm{s}} \mathrm{CPM}_{\text {init }} \mathrm{mL}_{\mathrm{fin}}}{\mathrm{mL}_{\text {init }} \mathrm{CPM}_{\mathrm{fin}}^{2} \mathrm{~g}_{\mathrm{p}}}\right)^{2}\left(\Delta \mathrm{CPM}_{\mathrm{fin}}\right)^{2} \\
& \left(\frac{\partial \mathrm{K}_{\mathrm{d}}}{\partial \mathrm{mL}}\right)_{\text {fin }}^{2}\left(\Delta \mathrm{mL}_{\mathrm{fin}}\right)^{2}=\left(\frac{\mathrm{mL}_{\mathrm{s}} \mathrm{CPM}_{\mathrm{init}}}{\mathrm{mL}_{\mathrm{init}} \mathrm{CPM}_{\mathrm{fin}} \mathrm{g}_{\mathrm{p}}}\right)^{2}\left(\Delta \mathrm{mL} \mathrm{fin}_{\mathrm{fin}}\right)^{2} \\
& \left(\frac{\partial \mathrm{K}_{\mathrm{d}}}{\partial \mathrm{g}_{\mathrm{p}}}\right)^{2}\left(\Delta \mathrm{g}_{\mathrm{p}}\right)^{2}=\left(\left[\frac{\mathrm{CPM}_{\mathrm{init}}}{\mathrm{mL} L_{\text {init }}}-\frac{\mathrm{CPM}_{\mathrm{fin}}}{\mathrm{mL}_{\mathrm{fin}}}\right] \frac{\mathrm{mL}_{\mathrm{s}} \mathrm{mL}_{\mathrm{fin}}}{\mathrm{g}_{\mathrm{p}}^{2} \mathrm{CPM}_{\mathrm{fin}}}\right)^{2}\left(\Delta \mathrm{g}_{\mathrm{p}}\right)^{2}
\end{aligned}
$$


and

$$
\begin{gathered}
\Delta \mathrm{mL}_{\mathrm{S}}=(0.6 \%) \mathrm{mL}_{\mathrm{S}} \\
\Delta \mathrm{mL}_{\text {init }}=\Delta \mathrm{mL}_{\mathrm{fin}}=(0.6 \%) \mathrm{mL} \\
\Delta \mathrm{CPM}=\frac{\sqrt{\mathrm{CPM} * \text { time }}}{\text { time }} \\
\Delta \mathrm{g}_{\mathrm{p}}=0.0001
\end{gathered}
$$

An alternative method for determining the uncertainty involves summing the relative errors of all the factors which can be quantified. This sum is the relative error of the $\mathrm{K}_{d}$ value. $\mathrm{K}_{\mathrm{d}}$ values can be expressed with their uncertainties as either a relative error (e.g., $2000 \pm 10 \%$ ) or the product of the $K_{d}$ value and the relative error (e.g., $2000 \pm 200$ ). The independent variables of $K_{d}$ can be written as in Eq. B-18.

$$
\mathrm{K}_{\mathrm{d}}=\mathrm{K}_{\mathrm{d}}\left(\mathrm{C}_{\mathrm{o}}, \mathrm{C}_{\mathrm{f}}, \mathrm{m}, \mathrm{V}_{\mathrm{a}}, \mathrm{V}, \mathrm{A}\right)
$$

where

$$
\begin{aligned}
& \mathrm{C}_{\mathrm{o}}=\text { initial stock solution count rate (before contact) } \\
& \mathrm{C}_{\mathrm{f}}=\text { final solution count rate (after contact) } \\
& \mathrm{V}=\text { contact volume of transuranic solution, } \mathrm{mL} \\
& \mathrm{m}=\text { mass of particles, } \mathrm{g} \\
& \mathrm{V}_{\mathrm{a}}=\text { volume of aliquot used for counting } \\
& \mathrm{A}=\text { active surface area of the particles }
\end{aligned}
$$

The active surface area of the particles (A) cannot be measured or estimated reliably. Poisson statistics may be applied to the count rates of the stock solution and the contacted sample supernatant. The standard deviation in Poisson statistics is the square root of the total number of counts in the peak. The relative uncertainty of the count rates is expressed as the standard deviation divided by the total area of the peak. The mass can be measured to within $0.0001 \mathrm{~g}$ on each measurement to yield relative errors on the order of $0.0002 / 0.0040=5 \%$. Each pipette transfer is approximately accurate to within $\pm 1 \%$. The total relative error for each $\mathrm{K}_{\mathrm{d}}$ value is $\sim 10 \%$. 


\section{APPENDIX C}

\section{OPTIMIZATION OF PARTICLE PREPARATION}

\section{Physical Parameter}

In some cases the inhomogeneity in particle batches was believed to be due to an insufficient volume of volatile liquid to promote adequate interaction between the particle surface area and the CMPO/TBP mixture. Tests were run with $\sim 15 \mathrm{~mL}$ of ethanol, i.e., low volume, and with $\sim 30 \mathrm{~mL}$ of ethanol, i.e., high volume. Next, the effect of the temperature was investigated. Initial temperatures of $\sim 65^{\circ} \mathrm{C}$ were used (low temperature). This was contrasted with high temperature evaporation at $>85^{\circ} \mathrm{C}$.

These tests did not yield conclusive evidence regarding the parameters tested. The best results were obtained by coating the particles with a sufficiently large volume of ethanol and evaporating at high temperatures. Through mean-free-path arguments the large volume is intuitively essential but the success of the high temperature evaporation might be due to a number of phenomena. These include a more thorough evaporation of the ethanol and the surpassing of an activation energy for adsorption onto the beads.

After this study, we focused on annealing as the essential stage in particle preparation. The systematic study of the annealing process showed that overall annealing at high temperature results in better extraction, as monitored by $\mathrm{K}_{\mathbf{d}}$ measurements. Part of the reason for this improvement may be (1) uniform coating of particles and (2) total evaporation of the carrier solvent.

However, our early annealing experiments on the chemisorption of CMPO/TBP onto magnetic microparticles gave mixed results. At times annealing increased the $\mathrm{K}_{d}$ and at other times it caused the $\mathrm{K}_{\mathrm{d}}$ to decrease.

A new coating procedure was established for coating larger batches (grams) of particles [TUAZON]. Each wash or separation is performed using a magnetic separator for filtering the particles.

1. Wash particles three times with deionized water, twice with $0.02-\mu \mathrm{m}$ filtered deionized water, and twice with $0.02-\mu \mathrm{m}$ filtered ethanol to remove the preservatives,

2. Dry overnight in a fume hood,

3. Grind the dried particles using a mortar and pestle,

4. Add $2 \mathrm{~mL}$ of $0.02-\mu \mathrm{m}$ filtered ethanol to 0.1 gram of particles in a teflon container, stirring the mixture until the particles are dispersed in the ethanol,

5. Add $0.25 \mathrm{~mL}$ of $1.2 \mathrm{M}$ CMPO/TBP solution to the particles,

6. Sonicate for $\sim 10$ minutes stirring the mixture constantly,

7. Heat in a water bath at $100^{\circ} \mathrm{C}$ until the ethanol is evaporated, stirring the mixture constantly,

8. Bake the particles in an oven at $120^{\circ} \mathrm{C}$ for 17 hours.

Following this procedure, a $\mathrm{K}_{\mathrm{d}}$ range of 4000 to 5000 for ${ }^{241} \mathrm{Am}$ in $2 \mathrm{M} \mathrm{HNO}_{3}$ solution is expected. The process has yielded the following $\mathrm{K}_{\mathrm{d}}$ values (Table C-1). 
Table C-1. $K_{d}$ Values Using New Annealing Process

\begin{tabular}{ccccccc}
\hline Sample ID & $\begin{array}{c}\text { Concentration } \\
\text { CMPO, } \underline{M}\end{array}$ & Mass, g & Stock CPM & $\begin{array}{c}\text { Background } \\
\text { CPM }\end{array}$ & Sample CPM & $\begin{array}{c}\mathrm{K}_{\mathrm{d}} \text {, } \\
\mathrm{mL} / \mathrm{g}\end{array}$ \\
\hline BAB 1107 114A & 1.2 & 0.0056 & 5996 & 186 & 793 & 3064 \\
BAB 1107 114B & 1.2 & 0.0049 & 5996 & 186 & 877 & 3024 \\
BAB 1107 122A & 1.2 & 0.0085 & 6527 & 186 & 518 & 4252 \\
BAB 1107 122B & 1.2 & 0.0067 & 6527 & 186 & 666 & 3649 \\
BAB 1107 122C & 1.2 & 0.0028 & 6527 & 186 & 1189 & 3804 \\
BAB 1107 122D & 1.2 & 0.0012 & 6527 & 186 & 1952 & 4318 \\
BAB 1107 122E & 1.2 & 0.0032 & 6527 & 186 & 1031 & 4065 \\
BAB 1107 122F & 1.2 & 0.0139 & 6527 & 186 & 357 & 5192 \\
HET 1169 62K & 1.36 & 0.0065 & 5977 & 193 & 662 & 3414 \\
HET 1169 63A & 1.36 & 0.0068 & 6724 & 179 & 613 & 4146 \\
HET 1169 63B & 1.36 & 0.0091 & 6724 & 179 & 525 & 3938 \\
HET 1169 63C & 1.36 & 0.0086 & 6724 & 179 & 706 & 2656 \\
HET 1169 63D & 1.36 & 0.0101 & 6724 & 179 & 604 & 2851 \\
HET 1169 63E & 1.36 & 0.0074 & 6724 & 179 & 802 & 2569 \\
HET 1169 63F & 1.36 & 0.0084 & 6724 & 179 & 720 & 2642 \\
HET 1169 63G & 1.36 & 0.0067 & 6724 & 179 & 793 & 2886 \\
\hline
\end{tabular}

The annealing process improved the $K_{d}$ values from less than 1000 before annealing to values between 2500 and 5200 after annealing, for the same extractant concentration.

The $\mathrm{K}_{\mathrm{d}}$ values for TRU extraction in $2 \mathrm{M} \mathrm{HNO}_{3}$ with CMPO/TBP-coated particles are reported in Table C-2. Also included for comparison are experimentally determined distribution ratios for americium with traditional liquid/liquid extraction using similar solutions. These results indicate better extraction performance by the MACS process than by the typical TRUEX solvent extraction process.

Table C-2. Partition Coefficients for TRU Extraction in 2M $\mathrm{HNO}_{3}$ with MACS Process and Comparison with Solvent Extraction Distribution Ratios ${ }^{a}$

\begin{tabular}{lccc}
\hline Tracer & $\begin{array}{c}\text { CMPcentration } \\
(\underline{\mathrm{M}})\end{array}$ & $\begin{array}{c}\text { Exp K } \\
\mathrm{mL} / \mathrm{g}\end{array}$ & $\operatorname{Exp~}_{\text {Am }}$ \\
\hline $241 \mathrm{Am}$ & 0.25 & 141 & 40 \\
$241 \mathrm{Am}$ & 0.75 & 3000 & 240 \\
$238 \mathrm{Pu}$ & 0.75 & 5500 & - \\
$241 \mathrm{Am}$ & 1 & 2704 & 360 \\
$241_{\mathrm{Am}}$ & 1.2 & 1924 & 1700 \\
$238 \mathrm{Pu}$ & 1.36 & 4000 & - \\
\hline
\end{tabular}

aThese results are before annealing, except for 1.36M CMPOcoated particles. $K_{d}(A m)$ values are between 3650 and 5192 , $\mathrm{K}_{\mathrm{d}}(\mathrm{Pu})$ are $>10,000$. 
APPENDIX D

NEUTRON ACTIVATION ANALYSIS

Instrumental neutron activation analysis (NAA) is a well-accepted technique capable of determining 30 to 40 elements including many environmentally crucial ones (e.g., aluminum, vanadium, zinc, copper, arsenic, antimony, chromium, selenium, iron, and nickel). The technique is also capable of determining major elements such as sodium, chlorine and potassium, as well as many rare earth elements. The determination of the elemental concentrations is based on the measurement of induced radioactivity. The radioactive decay of each induced isotope emits a characteristic gamma-ray energy spectrum. Hence an individual radionuclide "fingerprint" can be measured and quantified.

Activation analysis measures the total amount of an element in a material without regard to chemical or physical form. It has the following advantages: (1) samples for NAA can be liquids, solids or powders; (2) NAA is nondestructive and since no prechemistry is required, reagentintroduced contaminants are completely avoided; (3) NAA is a multi-elemental analytical technique in which many elements can be readily analyzed simultaneously; and (4) NAA is sensitive to trace elements. These factors have pushed the detection limits of most elements of interest to very low levels, not readily achievable by other analytical techniques. NAA is also totally unaffected by the presence of organic material in the sample, a significant problem in many types of conventional chemical methods.

The relative ease and precision (detection limits typically range from ppb to ppm) make NAA a useful method for determining metal content in aqueous samples. Aqueous samples typically have very low $\gamma$-ray backgrounds, allowing relatively low concentrations of metals to be measured. Neutron activation analysis measures a $\gamma$-ray spectrum produced by an irradiated sample and compares it with the spectra of standard reference materials to yield multi-elemental concentration information.

\section{Neutron-nuclei Reactions}

A variety of reactions may occur when a neutron collides with a nucleus. The reaction cross sections are a function of neutron energy and vary between target nuclei. The most common reactions are elastic scatter $(n, n)$, inelastic scatter $\left(n, n^{\prime}\right)$, radioactive capture $(n, \gamma)$, charged particle $(n, p)$ or $(n, \alpha)$, neutron multiplying $(n, 2 n)$, and fission (,$f)$. Radioactive capture reactions are most often used by NAA. The target nucleus $\mathrm{A}_{Z}$ absorbs a neutron $n$ and forms a compound nucleus ${ }^{A+1} Z^{*}$ in an excited state. A prompt $\gamma$ ray is emitted when the compound nucleus de-excites as shown in Eq. D-1.

$$
n+{ }^{A} Z \rightarrow{ }^{A+1} Z^{*} \rightarrow{ }^{A+1} Z+\gamma
$$

This prompt $\gamma$ ray is not used because its energy depends upon the energy of the incident neutron. To utilize the prompt $\gamma$ ray, a monoenergetic neutron source is required; this feature is not available at the University of Illinois at Urbana-Champaign (UIUC) TRIGA reactor facility. Neutron activation analysis measures the decay energy of one or more $\gamma$ rays from radioactive product nuclei $A+1 Z$. These radioactive decay photons emitted at specific energies for each radionuclide are detected with a high resolution $\gamma$-ray detector and stored as counts in a multi-channel analyzer (MCA) to produce a $\gamma$-ray spectrum. The peak energies in the spectrum identify the radioisotopes, and hence, the target nuclei $\mathrm{A}_{Z}$. The intensities of the peaks are used to determine the concentrations of the target nuclei. If a product nucleus is stable, NAA cannot be used to determine the concentration of the target element. 
Different stable target elements can undergo different reactions to produce the same product nucleus ${ }^{\mathrm{A}+1} \mathrm{Z}$. For example, ${ }^{28} \mathrm{Al}$ can be produced by the following three reactions:

$$
\begin{aligned}
& { }^{27} A l+n \rightarrow{ }^{28} A l+\gamma \\
& { }^{28} \mathrm{Si}+n \rightarrow{ }^{28} A l+p \\
& { }^{31} P+n \rightarrow{ }^{28} A l+\alpha .
\end{aligned}
$$

Reaction D-2 is the expected reaction while D-3 and D-4 are called interference reactions. Interference reactions increase the intensity of a $\gamma$-ray peak. The concentration of the desired target atom can still be determined by subtracting the contribution of the interference reactions from that of the isotope of interest.

\section{Reaction Rates}

The rate of neutron interactions $\left(R_{i}\right)$ of type $i$ is obtained by integrating the product of the interaction cross-section $\sigma_{i}(E)$, the neutron flux $\phi(E)$, and the number of target nuclei $N$ over the energy range of the incident neutrons.

$$
R_{i}=N \int_{0}^{\infty} \sigma_{i}(E) \phi(E) d E
$$

Concentrating on only radioactive capture reactions, the reaction rate is generally broken into three terms which depend on the energy ranges (thermal, epithermal, and fast) of the incident neutrons.

$$
R=R_{t h}+R_{e p i}+R_{\text {fast }}
$$

Many nuclides, especially those with low atomic number, have neutron capture cross sections which are proportional to $1 / \mathrm{v}$ for neutron energies below $0.5 \mathrm{eV}$, where $\mathrm{v}$ is the speed of the neutron. Generally the thermal cross section $\mathrm{s}_{\text {th }}$ corresponding to the thermal neutron energy $(0.025 \mathrm{eV})$ is used to determine the thermal reaction rate due to the thermal flux $\Phi_{\text {th }}$.

$$
R_{t h}=N \int_{t h} \sigma(E) \phi(E) d E=N \sigma_{t h} \Phi_{t h}
$$

Resonance peaks dominate the neutron capture cross sections at energies in the epithermal range between $0.5 \mathrm{eV}$ and $0.5 \mathrm{MeV}$. The epithermal neutron flux $\Phi_{\text {epi }}$ in a water moderated reactor like the TRIGA follows a $1 / \mathrm{E}$ distribution. Since the epithermal capture cross section $\mathrm{s}_{\mathrm{epi}}$ varies rapidly, the radioactive capture integral $I_{0}$ is used to refer to the cross section. The epithermal reaction rate can be calculated

$$
\begin{aligned}
R_{e p i} & =N \int_{e p i} \sigma(E) \phi(E) d E \\
& =N \int_{e p i} \sigma(E) \Phi_{e p i} d E / E \\
& =N \Phi_{e p i} \int_{e p i} \sigma(E) d E / E \\
& =N \Phi_{e p i} I_{o}
\end{aligned}
$$


where the epithermal flux $\Phi_{\text {epi }}$ is in units $\mathrm{n} /\left(\mathrm{s}^{\bullet} \mathrm{cm}^{2} \bullet \ln (\mathrm{E})\right)$. The fast reaction rate $\mathrm{R}_{\text {fast }}$ is negligible because the capture cross section at high energies is very small. The radioactive capture reaction rate can then be written as:

$$
R=N \sigma_{t h} \Phi_{t h}+N I_{o} \Phi_{e p i}
$$

Compilations of thermal neutron capture cross sections and resonance integrals are available from several references [MUGHABGHAB, IAEA] and increasingly in computer data bases.

In reactor based thermal irradiations, both terms in Eq. D-9 are important. The thermal reaction rate term is eliminated for epithermal irradiations. By employing a cadmium filter, neutrons below energy $0.55 \mathrm{eV}$ are removed from the flux. Irradiations executed in this manner are called epithermal. In the epithermal region, neutron cross sections do not strictly follow the $1 / \mathrm{v}$ rule. Some elements possess large resonance peaks superimposed on the $1 / v$ continuum in the epithermal range. Such an element is said to have a large resonance integral $\mathrm{I}_{0}$. Elements with large resonance integral to thermal neutron cross section ratios, $I_{0} / \sigma_{\text {th }}$, are very sensitive to epithermal neutron activation analysis (ENAA).

\section{Calculation of Concentrations by NAA}

The expressions for reaction rates developed in the preceding section can be used to calculate the concentration of an element in an unknown sample from knowledge of the concentration of the element in a reference standard. The reaction rate for a specific target can be written:

$$
R=N \sigma_{t h} \Phi_{t h}+N I_{o} \Phi_{e p i}=N \sigma_{a c t} \Phi
$$

where $\sigma_{\text {act }} \Phi$ is the product of the activation cross section and the neutron flux integrated over the appropriate energy range. The rate of change in the number of radioactive nuclei $\mathrm{N}^{*}$ is given by Eq. D-11 where $\lambda$ is the radioactive decay constant.

$$
\frac{d N^{*}}{d t}=\sigma_{a c t} \Phi N-\lambda N^{*}
$$

Integrating Eq. D-11 to obtain $\mathrm{N}^{*}=\mathrm{N}^{*}(\mathrm{t})$ yields:

$$
N^{*}(t)=\frac{\sigma_{a c t} \Phi N}{\lambda}\left(1-e^{-\lambda t}\right)
$$

In practical applications, a sample is irradiated for a time $t_{i}$, allowed to cool during a decay time $t_{d}$, and counted for a time $t_{c}$. These three time variables are chosen to optimize the analytical sensitivity of the radionuclides of interest. The number of radioactive nuclei which decay during a counting time $t_{c}$ is given by Eq. D-13.

$$
N^{*}=\frac{\sigma_{a c t} \Phi N}{\lambda}\left(1-e^{-\lambda t_{i}}\right) e^{-\lambda t_{d}}\left(1-e^{-\lambda t_{c}}\right)
$$

The count measured depends upon the intensity of the emitted $\gamma$ rays at a given energy $I_{\gamma}$ and the efficiency $\varepsilon_{\gamma}$ of the detector for this $\gamma$ ray. Combining these factors with the previous expression yields the following result for counts measured:

$$
N^{*}=\frac{\sigma_{a c t} \Phi N}{\lambda}\left(1-e^{-\lambda t_{i}}\right) e^{-\lambda t_{d}}\left(1-e^{-\lambda t_{c}}\right) I_{\gamma} \varepsilon_{\gamma}
$$


Typically, comparative methods such as NAA irradiate standards and samples together and count both using identical geometric configurations with the same detector. Then the ratio of unknown (sample) counts to known (standard) counts measured is:

$$
\frac{N_{u}^{*}}{N_{k}^{*}}=\frac{N_{u}}{N_{k}} \frac{e^{-\lambda t_{d u}}}{e^{-\lambda t_{d k}}} \frac{\left(1-e^{-\lambda t_{c u}}\right)}{\left(1-e^{-\lambda t_{c k}}\right)}
$$

The number of target nuclei $\mathrm{N}$ is a product of concentration $\mathrm{C}$ and mass $\mathrm{M}$. If samples and standards are counted for the same length of time, Eq. D-15 can then be rewritten solving for the concentration of the unknown sample:

$$
C_{u}=C_{k} \frac{M_{k}}{M_{u}} \frac{N_{u}^{*}}{N_{k}^{*}} \frac{e^{-\lambda t_{d u}}}{e^{-\lambda t_{d k}}}
$$

where the subscripts $\mathrm{u}$ and $\mathrm{k}$ denote unknown sample and known standard, respectively. If the sample and standards are irradiated at different times, then flux monitors are employed to account for any variations in neutron fluence.

\section{Detection System}

Spectra of the radioactive samples are collected with high purity germanium (HPGe) detectors. Photons entering the HPGe detector can undergo three different interactions: photoelectric effect, Compton effect or pair production. Low energy $\gamma$ rays most often interact by the photoelectric effect. The incident photon transfers all its energy to an inner orbital electron in the detector. The ejected electron, and the x-rays or Auger electrons produced as outer electrons fill the hole it left, have short ranges, usually depositing all of their energy in the HPGe detector. If all the energy from the incident photon is deposited in the detector, a photopeak of the initial $\gamma$ ray is produced. Neutron activation analysis uses the photopeak produced to measure the counts C referred to in Eq. D- 16 .

The Compton effect is an inelastic scattering interaction between the incident photon and an orbital electron in which the initial photon energy is split between the scattered photon and recoil electron. The partitioning of energy depends upon the angle $\theta$ at which the photon is scattered. All scattering angles are possible. The wavelength of the scattered photon $\lambda_{\mathrm{s}}$ in terms of the wavelength of the incident photon $\lambda_{i}$ and angle between their paths is:

$$
\lambda_{s}=\lambda_{i}+\frac{h c}{m_{e} c^{2}}(1-\cos \theta)
$$

where $h$ is Plank's constant, $c$ is the speed of light, and $m_{e}$ is the rest mass of an electron. The scattered photon always has a longer wavelength (and therefore lower energy) than the incident photon. The recoil electron has a short range and generally deposits all its energy in the HPGe detector. The scattered gamma ray may interact via the photoelectric effect, or by a second Compton event, or may escape from the detector. A photoelectric interaction produces a full energy photopeak. A second Compton scatter produces a repeat of these three possibilities. Escape from the detector by the scattered photon produces the elevated background of the Compton continuum.

Pair production is an interaction between a high energy photon and the field of the target nucleus. When the photon energy is greater than $2 \mathrm{~m}_{\mathrm{e}} \mathrm{c}^{2}=1.022 \mathrm{MeV}$, the photon can disappear with the creation of an electron-positron pair. Any energy above $1.022 \mathrm{MeV}$ is transferred to the kinetic energy of the pair. The electron and positron may stop in the HPGe detector, but frequently one or both of the $0.511 \mathrm{MeV}$ photons released by the annihilation of the positron with an electron escape the detector. Single or double escape peaks, $0.511 \mathrm{MeV}$ and $1.022 \mathrm{MeV}$ below the photopeak, are 
frequently present in the spectrum. These escape peaks sometimes interfere with the photopeaks created by lower energy photons. 


\section{APPENDIX E}

\section{ERROR FUNCTION FOR $\mathrm{K}_{\mathrm{d}}$ STRIP EXPERIMENTS}

The expression for the error in $\mathrm{K}_{\mathrm{d}}$ strip was derived from radiation counting statistics presented by Tsoulfanidis [TSOULFANIDIS, ANDERSON]. The assumptions made were similar to those made for $K_{d}$ extraction, i.e., the errors in pipet calibration and pipetting technique were considered negligible. The $\mathrm{K}_{\mathrm{d}}$ strip equation and the subsequent error derivation are presented below.

$$
\mathrm{K}_{\mathrm{d}}^{\mathrm{s}}=\frac{\left(\frac{\left.\mathrm{m}_{\mathrm{p}} \mathrm{K}_{\mathrm{d}}^{\mathrm{e}} \mathrm{C}_{\mathrm{f}}^{\mathrm{e}}-\mathrm{C}_{\mathrm{f}}^{\mathrm{s}}\right)}{0.5 \mathrm{~mL}}\right.}{\frac{\mathrm{m}_{\mathrm{p}}}{0.5 \mathrm{~mL}} \mathrm{C}_{\mathrm{f}}^{\mathrm{s}}}=\frac{\mathrm{K}_{\mathrm{d}}^{\mathrm{e}} \mathrm{C}_{\mathrm{f}}^{\mathrm{e}}}{\mathrm{C}_{\mathrm{f}}^{\mathrm{s}}}-\frac{0.5 \mathrm{~mL}}{\mathrm{~m}_{\mathrm{p}}}
$$

Where the superscript $e$ and $s$ refer to extraction and stripping, respectively. The aliquot counts are denoted by $\mathrm{C}_{f}$ and the mass of particles used by $\mathrm{m}_{\mathrm{p}}$. The $0.5 \mathrm{~mL}$ comes from the volume of stripping agent used. In general, the error function is written as:

$$
\left(\Delta \mathrm{K}_{\mathrm{d}}^{\mathrm{s}}\right)^{2}=\left(\frac{\delta \mathrm{K}_{\mathrm{d}}^{\mathrm{s}}}{\delta \mathrm{K}_{\mathrm{d}}^{\mathrm{e}}}\right)^{2}\left(\Delta \mathrm{K}_{\mathrm{d}}^{\mathrm{e}}\right)^{2}+\left(\frac{\delta \mathrm{K}_{\mathrm{d}}^{\mathrm{s}}}{\delta \mathrm{C}_{\mathrm{f}}^{\mathrm{e}}}\right)^{2}\left(\Delta \mathrm{C}_{\mathrm{f}}^{\mathrm{e}}\right)^{2}+\left(\frac{\delta \mathrm{K}_{\mathrm{d}}^{\mathrm{s}}}{\delta \mathrm{C}_{\mathrm{f}}^{\mathrm{s}}}\right)^{2}\left(\Delta \mathrm{C}_{\mathrm{f}}^{\mathrm{s}}\right)^{2}+\left(\frac{\delta \mathrm{K}_{\mathrm{d}}^{\mathrm{s}}}{\delta \mathrm{m}_{\mathrm{p}}}\right)^{2}\left(\Delta \mathrm{m}_{\mathrm{p}}\right)^{2}
$$

Performing the differentiation gives:

$$
\left(\Delta \mathrm{K}_{\mathrm{d}}^{\mathrm{s}}\right)^{2}=\left(\frac{\mathrm{C}_{\mathrm{f}}^{\mathrm{e}}}{\mathrm{C}_{\mathrm{f}}^{\mathrm{s}}}\right)^{2}\left(\Delta \mathrm{K}_{\mathrm{d}}^{\mathrm{e}}\right)^{2}+\left(\frac{\mathrm{K}_{\mathrm{d}}^{\mathrm{e}}}{\mathrm{C}_{\mathrm{f}}^{\mathrm{s}}}\right)^{2}\left(\Delta \mathrm{C}_{\mathrm{f}}^{\mathrm{e}}\right)^{2}+\left(\frac{\mathrm{K}_{\mathrm{d}}^{\mathrm{e}} \mathrm{C}_{\mathrm{f}}^{\mathrm{e}}}{\left(\mathrm{C}_{\mathrm{f}}^{\mathrm{s}}\right)^{2}}\right)^{2}\left(\Delta \mathrm{C}_{\mathrm{f}}^{\mathrm{s}}\right)^{2}+\left(\frac{0.5 \mathrm{~mL}}{\mathrm{~m}_{\mathrm{p}}{ }^{2}}\right)^{2}\left(\Delta \mathrm{m}_{\mathrm{p}}\right)^{2}
$$

Grouping terms together and simplifying gives:

$$
\left(\Delta \mathrm{K}_{\mathrm{d}}^{\mathrm{s}}\right)^{2}=\left(\frac{1}{\mathrm{C}_{\mathrm{f}}^{\mathrm{s}}}\right)^{2}\left[\left(\mathrm{C}_{\mathrm{f}}^{\mathrm{e}} \Delta \mathrm{K}_{\mathrm{d}}^{\mathrm{e}}\right)^{2}+\left(\mathrm{K}_{\mathrm{d}}^{\mathrm{e}} \Delta \mathrm{C}_{\mathrm{f}}^{\mathrm{e}}\right)^{2}+\left(\frac{\mathrm{K}_{\mathrm{d}}^{\mathrm{e}} \mathrm{C}_{\mathrm{f}}^{\mathrm{e}} \Delta \mathrm{C}_{\mathrm{f}}^{\mathrm{s}}}{\mathrm{C}_{\mathrm{f}}^{\mathrm{s}}}\right)^{2}\right]+\left(\frac{0.5 \mathrm{~mL}}{\mathrm{~m}_{\mathrm{p}}{ }^{2}}\right)^{2}\left(\Delta \mathrm{m}_{\mathrm{p}}\right)^{2}
$$

where $\Delta \mathrm{K}_{\mathrm{d}}^{\mathrm{e}}=$ the extraction partition coefficient

$$
\begin{aligned}
\Delta C_{f}^{e} & =0.5 \% \text { standard deviation of } C_{f}^{e} \\
\Delta C_{f}^{s} & =0.5 \% \text { standard deviation of } C_{f}^{s} \\
\Delta m_{p} & =0.0001 \mathrm{~g}
\end{aligned}
$$

Note: The $0.5 \%$ is the deviation set by the gamma counter. 
Equation E-4 is believed to underestimate the error due to the difficulty encountered in recovering the beads for stripping experiments. However, once the stripping procedure has been perfected, the error function for $K_{d}$ strip will be very useful in our data analysis.

A sample calculation is provided below. The data for 1.2ㅆ CMPO/TBP is presented in Table E-1 for convenience.

Using $\mathrm{E}-4$, the extraction error is determined $\Delta \mathrm{K}_{\mathrm{d}}$,extract $=36$. Using this value and the error assumptions for mass and counts, the computed stripping error is $\Delta K_{d}$ strip $=2$. It is important to emphasize that the loss of particles after the extraction is ignored. Consequently, the only contribution to the error in the mass of particles is that associated with the balance. The reported $\mathrm{K}_{\mathrm{d}}$ would be $0.73 \pm 2$.

Table E-1. 1.0 $\underline{\mathrm{M}}$ CMPO Extraction and Stripping Data

\begin{tabular}{lccccccccc}
\hline $\begin{array}{l}\text { Stripping } \\
\text { Solvent }\end{array}$ & $\begin{array}{c}\text { Bkg } \\
\text { CPM }\end{array}$ & $\begin{array}{c}\text { Stock } \\
\text { CPM }\end{array}$ & $\begin{array}{c}\text { Loading, } \\
\text { mL/g }\end{array}$ & $\begin{array}{c}\text { Loading } \\
\text { CPM }\end{array}$ & $\begin{array}{c}\text { Ave. Sample } \\
\text { CPM }\end{array}$ & $\begin{array}{c}\text { Particle } \\
\text { mass, g }\end{array}$ & $\begin{array}{c}\text { Stripping, } \\
\text { mL/g }\end{array}$ & $\begin{array}{c}\text { Vol Extr, } \\
\mathrm{mL}\end{array}$ & $\begin{array}{c}\text { Vol Strip, } \\
\mathrm{mL}\end{array}$ \\
\hline Ethanol & 175 & 5907 & 1850 & 756 & 18527.5 & 0.0084 & 0.73 & 10 & 0.025 \\
\hline
\end{tabular}




\section{DEFINITIONS}

Absorption: To receive or incorporate particles/molecules into matter

Adsorption: accumulation of particles/molecules at a surface. Mechanisms for such an accumulation are chemisorption and physisorption.

A/O ratio: Volume of aqueous to organic phase

Aqueous feed: The aqueous solution sent into the extraction stage which contains the metals of interest to be separated

Contactor: A device for dispersing and disengaging immiscible solution mixtures (e.g., liquid/liquid, liquid/solid), it may be single or multistage

Countercurrent extraction: A multistage solvent extraction process in which organic and aqueous phases flow from stage to stage in opposite directions

Diluent: The organic fluid in which an extractant and modifier are dissolved to form a solvent

Desorption: Removal of materials from a surface

Distribution: The partitioning of a species (solute) into two phases

Extractant: The active organic components that separate the species of interest

Load: To transfer a metal from an aqueous to an organic (or solid) phase

Loaded solvent: The organic solvent containing the maximum concentration of a metal for a given extraction condition

Loading capacity: saturation limit of a solvent for a metal

Modifier: A substance added to a solvent to increase the solubility of the extractant, or the extracted species during any stage of the separation process

Partition coefficient: The ratio of the concentration of a solute in the solid phase to the concentration of the same form in the aqueous phase. Separation factor ratio of the distribution coefficients of two metals being compared

Stripping: Removal of the extracted metal from the loaded solvent

Synergism: The cooperative effect of two (or more) extractants that exceed the sum of the individual effects

Regeneration stage: Solvent contacted with a solution or solid that restores the chemical properties to that necessary for efficient extraction. 


\section{REFERENCES}

\section{ALLCOCK}

H. R. Allcock and F. W. Lampe, Contemporary Polymer Chemistry, Prentice-Hall, Inc., New Jersey, pp. 571-577 (1981).

\section{ANDERSON}

R. L. Anderson, Practical Statistics for Analytical Chemists, Van Nostrand Reinhold, New York (1987).

BOYD

T. E. Boyd and R. L. Klochen, Ferrite Treatment of Actinide Waste Solutions: Continuous Processing of Rocky Flats Process Waste, Report No. RFP-3476, Rockwell International, Rocky Flats Plant, Golden, CO, March 18, 1983.

BURNS

M. Burns and D. Putnam, A Microscopic Study of Particle Filtration in a Magnetically Stabilized Fluidized Bed, University of Michigan, Ann Arbor, MI (1992).

CEMBER

H. Cember, Introduction to Health Physics, Pergamon, New York, pp. 97-109 (1983).

CLEVELAND

J. M. Cleveland, The Chemistry of Plutonium, American Nuclear Society, La Grange

Park, IL (1979).

\section{DUPRE}

G. Dupre, J. Pirkle, and J. Siegell, Chromatographic Separations in a Crossflow Magnetically Stabilized Bed, Exxon Research and Engineering Company, Florham Park, NJ (1986).

EPST

Encyclopedia of Polymer Science and Technology, Wiley-Interscience Publication, New York, Vol. 1, pp. 170-267 (1964)

HORWTTZ-A

E. P. Horwitz, and W. W. Schulz, "The TRUEX Process: A Vital Tool for Disposal of U. S. Defense Nuclear Waste," New Separation Chemistry Techniques for Radioactive Waste and Other Specific Application., L. Cecille, M. Casarci, and L. Pietrelli, Eds., Elsevier Applied Science, London and New York, pp. 21-29 (1992).

\section{HORWITZ-B}

E. P. Horwitz, H. Diamond, and K. A. Martin, "The Extraction of Selected Actinides in the (III) (IV) and (VI) Oxidation States from Hydrochloric Acid by OfD(iB)CMPO: The TRUEXChloride Process," Solvent Extraction and Ion Exchange 5(3), 447-470 (1987).

IAEA

Handbook on Nuclear Activation Data, IAEA Technical Reports Series No. 273, International Atomic Energy Agency, Vienna, Austria (1987).

\section{KIRK-OTHMER-A}

Encyclopedia of Chemical Technology, Wiley-Interscience Publication, New York, Vol. 4, p. 541 (1978).

\section{KIRK-OTHMER-B}

Encyclopedia of Chemical Technology, Wiley-Interscience Publication, New York, Vol. 18, p. 731 (1978). 
KIRK-OTHMER-C

Encyclopedia of Chemical Technology, Wiley-Interscience Publication, New York, Vol. 1. pp. 170-178 (1978).

\section{KOCHEN}

R. L. Klochen, Actinide Removal from Aqueous Solution with Activated Magnetite, RFP-4100, Rockwell International, Rocky Flats Plant, Golden, CO, August 10, 1987.

\section{LEONARD}

R. Leonard, G. F. Vandegrift, D. G. Kalina, D. F. Fischer, R. W. Bane, L. Burris, E. P. Horwitz, R. Chiarizia, and H. Diamond, The Extraction and Recovery of Plutonium and Americium from Nitric Acid Waste Solutions by the TRUEX Process - Continuing Development Studies, Argonne National Laboratory Report, ANL-85-45, p. 9 (1985).

LUND

A. Lund, Y. Wasteson, and O. Olsvik, "Immunomagnetic Separation and DNA Hybridization for Detection of Enterotoxigenic Escherichia Coli in a Piglet Model," J. Clin. Microbiol. $29(10), 2259$ (1991).

\section{McCABE}

W. L. McCabe, J C. Smith, and P. Harriot, Transport Phenomena, McGraw-Hill, New York (1993).

\section{MUCHABGHAB}

S. F. Mughabghab, M. Divadeenam and N. E. Holden, Neutron Cross Sections, Vol. 1: Neutron Resonance Parameters and Thermal Cross Sections; Part A: $Z=1$ - 60 and Part B: $Z=60 \cdot 100$, Academic Press, New York and Orlando, FL (1984).

\section{MORSS}

L. R. Morss, The Chemistry of the Actinide Elements, 2nd Ed., J. J. Katz, G. T. Seaborg, and

L. R. Morss, Eds., Chapman and Hall, New York, Chapter 17, Vol. II, (1986).

\section{NUNEZ-1993}

L. Nuñez, B. A. Buchholz, and G. F. Vandegrift, "Waste Remediation Using In-Situ Magnetically Assisted Chemical Separation," Proceedings of the Eighth Symposium on Separation Science and Technology, Gatlinburg, TN (1993).

\section{NUNEZ-1994A}

L. Nuñez, B. A. Buchholz, M. Kaminski, S. B. Aase, N. R. Brown, and G. F. Vandegrift, "Actinide Separation of High Level Waste using Solvent Extractants on Magnetic Microparticles," Proceedings of American Chemical Society High Level Waste Washington, DC, August 1994 (1994).

\section{NUNEZ-1994B}

L. Nuñez and G. F. Vandegrift, "Plutonium and Americium Separation using Organophosphorus Extractants Absorbed onto Ferromagnetic Particles, f-Elements Separation," Proceedings of American Chemical Society Meeting, San Diego, CA, March 1994 (1994).

\section{PAINE}

R. T. Paine, "Polymeric Materials for Metal Ion Separations," Solvent Extraction and Ion Exchange, 7, 925(1989).

\section{PIETRELLI}

L. Pietrelli, A. Salluzzo, and F. Troiani, "Actinides Removal by Means of Octyl(phenyl)-N,Ndiisobutylcarbamoylmethylphosphine Oxide (CMPO) Sorbed on Silica," New Separation Chemistry Techniques for Radioactive Waste and Other Applications, Elsevier Sci. Publishing Co, London (1991). 
RYDBERG

J. Rydberg, C. Musikas, and G. R. Choppin, Principle and Practices of Solvent Extraction, Marcel Dekker Inc., New York (1992).

\section{SCHULZ}

W. W. Schulz, J. D. Navratil, and T. Bess, Science and Technology of Tributyl Phosphate

Vol. II: Part B, CRC Press, Boca Raton, FL (1987).

STABLER

T. V. Stabler and A. L. Siegel "Chemiluminescence Immunoassay of Aldosterone in Serum," Clin. Chem. 37(11), 1987 (1991).

SKJERVE

E. L. Skjerve, L. M. Rorvik, and O. Olsvik "Detection of Listeria monocyntogenes in Foods by Immunomagnetic Separation," Appl. Environ. Microbiol. 56, 3478 (1990).

\section{TSOULFANIDIS}

N. Tsoulfanidis, Measurement and Detection of Radiation, Hemisphere Publishing Corporation, New York (1983).

TUAZON

H. Tuazon, ANL undergraduate research, May 1993.

VANDEGRIFT-1984

G. F. Vandegrift, R. A. Leonard, M. J. Steindler, E. P. Horwitz, L. T. Basile, H. Diamond,

D. G. Kalina, and L. Kaplan, Transuranic Decontamination of Nitric Acid Solution by the TRUEX Solvent Extraction Process-Preliminary Development Studies, Argonne National Laboratory Report, ANL-84-45 (1984).

VANDEGRIFT-1990

G. F. Vandegrift, D.J. Chaiko, et al., ANL, unpublished information (1990).

VANDEGRIFT-1993

G. F. Vandegrift, D. B. Chamberlain, C. Conner, J. M. Copple, J. A. Dow, L. Everson, J. C. Hutter, R. A. Leonard, L. Nuñez, J. M. Copple, J. A. Dow, B. Srinivasan, M. C. Regalbuto, and S. Weber, "Development and Demonstration of the TRUEX Solvent Extraction Process," Proceedings of Waste Management Symposia, Tuscon, AZ (1993). 


\section{Distribution for ANL-95/1}

Internal:

S. Aase

J. E. Battles

B. A. Buchholz

G. Dyrkacz

J. E. Harmon
M. D. Kaminski

J. J. Laidler

L. Nunez (20)

M. J. Steindler
C. E. Till

H. E. Tuazon

G. F. Vandegrift

TIS Files

\section{External:}

DOE-OSTI (2)

ANL-E Library (2)

ANL-W Library

Manager, Chicago Operations Office, DOE

J. Haugen, DOE-CH

Chemical Technology Division Review Committee Members:

E. R. Beaver, Monsanto Company, St. Louis, MO

D. L. Douglas, Consultant, Bloomington, $\mathrm{MN}$

R. K. Genung, Oak Ridge National Laboratory, Oak Ridge, TN

J. G. Kay, Drexel University, Philadelphia, PA

G. R. St. Pierre, Ohio State University, Columbus, $\mathrm{OH}$

J. Stringer, Electric Power Research Institute, Palo Alto, CA

J. B. Wagner, Arizona State University, Tempe, AZ

F. M. Bos, Bradtec, Inc., Atlanta, GA

P. Colton, Pacific Northwest Laboratory, Richland, WA

T. Fryberger, USDOE, Office of Technology Development, Germantown, MD

W. L. Kuhn, Pacific Northwest Laboratory, Richland, WA

S. Landsberger, University of Illinois, Urbana, IL

I. R. Tasker, Waste Policy Institute, Gaithersburg, MD

J. Watson, Oak Ridge National Laboratory, Oak Ridge, TN 